\title{
Effect of dealumination on the catalytic performance of Cr-containing Beta zeolite in carbon dioxide assisted propane dehydrogenation
}

\author{
Piotr Michorczyk $^{\mathrm{a},}{ }_{*}$, Kamila Zeńczak-Tomera ${ }^{\mathrm{a}}$, Barbara Michorczyk ${ }^{\mathrm{a}}$, Adam Węgrzyniak ${ }^{\mathrm{a}}$, Marcelina Basta ${ }^{\mathrm{a}}$, \\ Yannick Millot ${ }^{\mathrm{b}}$, Laetitia Valentin ${ }^{\mathrm{b}}$, Stanislaw Dzwigaj ${ }^{\mathrm{b}}{ }_{*}$ \\ a Institute of Organic Chemistry and Technology, Cracow University of Technology, Warszawska 24, 31-155 Kraków, Poland \\ ${ }^{\mathrm{b}}$ Laboratoire de Réactivité de Surface, Sorbonne Université-CNRS, UMR 7197, 4 place Jussieu, Case 168, F-75252 Paris, France
}

\section{A R T I C L E I N F O}

\section{Keywords:}

Propene

Dehydrogenation

Utilization of $\mathrm{CO}_{2}$

Beta zeolite

Chromium oxide-based catalyst

\begin{abstract}
A B S T R A C T
New active and selective catalysts for propane to propene dehydrogenation in assistance of $\mathrm{CO}_{2}\left(\mathrm{CO}_{2}-\mathrm{PDH}\right)$ were prepared by chromium incorporation in siliceous SiBeta. The Cr-containing SiBeta zeolite catalysts were obtained by two-step postsynthesis preparation procedure which consist, in the first step, removal of aluminum from TEABeta zeolite with $\mathrm{Si} / \mathrm{Al}$ of 17 by treatment with nitric acid solution to obtain an aluminium-free SiBeta support with $\mathrm{Si} / \mathrm{Al}$ ratio of 1000 and, in the second step, various amounts of $\mathrm{Cr}$ were introduced into the siliceous SiBeta zeolite structure by wet impregnation. The well correlation between the number of redox $\mathrm{Cr}$ sites and propene yield up to $2 \mathrm{wt} \%$ of $\mathrm{Cr}$ has been determined. Comparing of catalytic activity of Cr-containing Beta zeolite catalysts with the identical $\mathrm{Cr}$ content ( $2 \mathrm{wt} \%$ of $\mathrm{Cr}$ ) supported on SiBeta and AlBeta revealed that the dealumination has great impact on catalytic properties. Low acidity of SiBeta is suitable for achieving high selectivity to propene (above $80 \%$ ) while high acidity of starting AlBeta promotes propane cracking to lighter hydrocarbons. Moreover, in switch operation mode between propane dehydrogenation in presence and absence of $\mathrm{CO}_{2}$ the formation rate of propene raises in mode with $\mathrm{CO}_{2}$ only over Cr-containing SiBeta zeolite catalyst, while over Cr-containing AlBeta zeolite catalyst a negative effect on the rate of propene formation was observed.
\end{abstract}

\section{Introduction}

Nowadays unsaturated hydrocarbons are basic and most important intermediates for chemical industry. Particularly, the demand for propene has been growing since it has found an assured position on the chemical raw material and monomers market due to its numerous uses. Worldwide demand for propene currently reaches 90 million tonnes per year and at an estimated growth rate of about $5 \%$ annually, will reach a value of around 130 million tonnes by 2023 [1]. It is estimated that such high demand for propene won't be satisfied by its current two most important sources, that is, steam cracking and catalytic cracking, in which propene is obtained as co-products. Attempts at increasing propene production, e.g. through optimisation of conditions of these processes, will negatively influence the production of other important co-products. Thus, selective processes dedicated solely to propene synthesis, such as propane dehydrogenation, olefin metathesis, and propene synthesis using methanol (e.g. MTP methanol-to-propene), will gain significance with time.

Concerns connected to meeting demand for propene without simultaneously decreasing production of remaining valuable products also favour intensification of fundamental research. One of the crucial research directions is the development of a new selective process of obtaining propene from propane that could replace propane dehydrogenation process $(\mathrm{PDH})$ currently used for industrial needs. However, this process has disadvantages such as reversibility and endothermalness. An attractive alternative for the traditional $\mathrm{PDH}$ is propane oxidative dehydrogenation in the presence of $\mathrm{O}_{2}(\mathrm{ODH})$ or propane dehydrogenation in the presence of $\mathrm{CO}_{2}\left(\mathrm{CO}_{2}-\mathrm{PDH}\right)$. A shared characteristic of all the aforementioned processes is utilising a co-reagent that either removes PDH thermodynamic limits or increases production through hydrogen binding in consecutive reactions. Typically in this process per-

\footnotetext{
* Corresponding authors.

Email addresses: pmichor@pk.edu.pl (P. Michorczyk); stanislaw.dzwigaj@upmc.fr (S. Dzwigaj)
} 


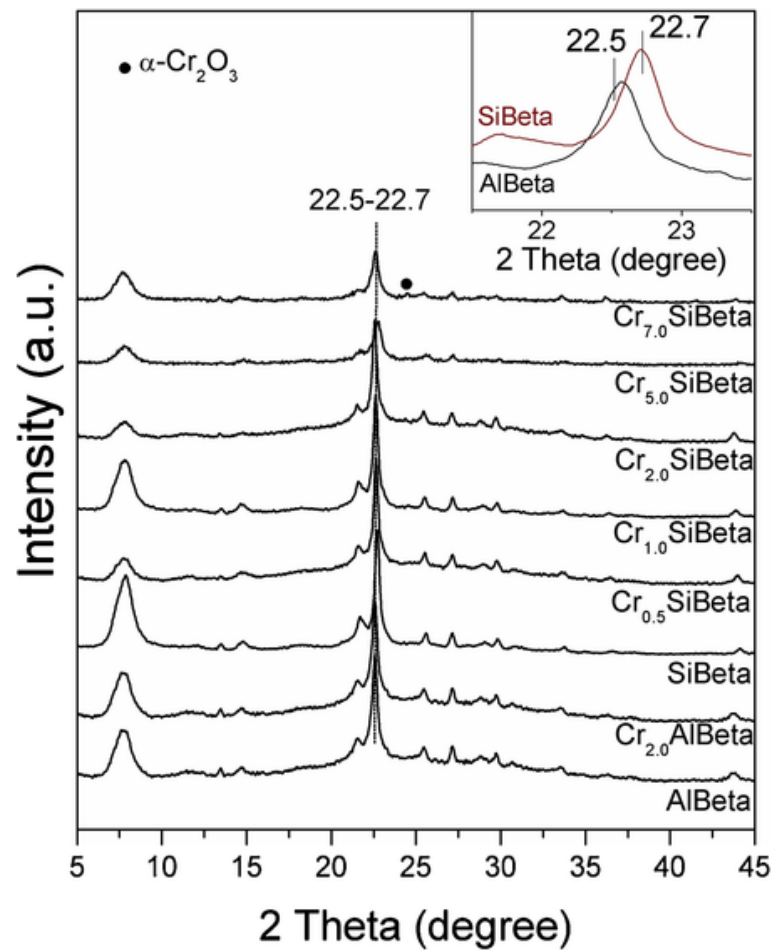

Fig. 1. XRD of AlBeta, SiBeta, $\mathrm{Cr}_{0.5} \mathrm{SiBeta}, \mathrm{Cr}_{1.0} \mathrm{SiBeta}, \mathrm{Cr}_{2.0} \mathrm{SiBeta}, \mathrm{Cr}_{5.0} \mathrm{SiBeta}$ and $\mathrm{Cr}_{7.0} \mathrm{Si}-$ Beta recorded at room temperature and ambient atmosphere.

pass conversion of propane and yield of propene are higher than in commercial non-oxidative dehydrogenation. Moreover, due to large scale propene production the process can be attractive way for chemical $\mathrm{CO}_{2}$ utilisation, because in addition to propene, hydrogen and carbon monoxide (syngas) are produced as the main products. Some possibility of $\mathrm{CO}_{2}-\mathrm{PDH}$ integration with syngas or propene required processes are proposed previously [2].

Many different catalysts were investigated in $\mathrm{CO}_{2}-\mathrm{PDH}$ containing Pt [3], Ni-Fe [4] Cr [5-16], Ga [17-20], In-Al [21-23], Fe [24] or V
$[25,26]$. Among them, the chromium oxide-based materials are considered as a very promising for $\mathrm{CO}_{2}-\mathrm{PDH}$ due to high activity and selectivity. The mechanism of propane dehydrogenation in presence of $\mathrm{CO}_{2}$ is complex. Various possible scenarios of the $\mathrm{CO}_{2}-\mathrm{PDH}$ in which propene is produced either by non-oxidative dehydrogenation with participation of $\mathrm{Cr}(\mathrm{II})$ or/and $\mathrm{Cr}(\mathrm{III})$ species or by various redox mechanisms with participation of carbon dioxide as a mild oxidant in an oxidative dehydrogenation pathway have been proposed [10,27-31]. In the oxidative pathway various redox cycles between the oxidised/reduced forms of $\mathrm{Cr}$ sites, such as $\mathrm{Cr}(\mathrm{III}) / \mathrm{Cr}(\mathrm{II}), \mathrm{Cr}(\mathrm{VI}) / \mathrm{Cr}(\mathrm{III})$ or $\mathrm{Cr}(\mathrm{V}) / \mathrm{Cr}(\mathrm{III})$ has been suggested. It has been recognized that high dispersion and presence of redox chromium species are important factors for achieving high catalytic performance in $\mathrm{CO}_{2}-\mathrm{PDH}[18,27,28]$. From above reasons chromium is typically dispersed on a support. Very good support ensuring high chromium dispersion is silica, particularly of ordered mesoporous structure. Due to large specific surface area (in the most cases above $1000 \mathrm{~m}^{2} \mathrm{~g}^{-1}$ ) of mesoporous materials like MCM-41, SBA-1, SBA-15 or $\mathrm{MSU}_{\mathrm{x}}$ a high dispersion and concentration of chromium oxide species can be obtained in comparison to unordered silica support $[6,9,10,14,18,27,28]$. Others tested support, for instance $\gamma-\mathrm{Al}_{2} \mathrm{O}_{3}$, which is commercially used for chromium dispersion in $\mathrm{PDH}$ catalyst (CATOFIN Process) or active carbon are less useful. Over $\gamma-\mathrm{Al}_{2} \mathrm{O}_{3}$ supported chromium oxide catalysts $\mathrm{CO}_{2}$ addition exerts poisoning effect while in the case of active carbon supported catalyst an application in $\mathrm{CO}_{2}-\mathrm{PDH}$ is limited by period regeneration with air $[5,11,32]$.

In this work Cr-containing Beta zeolites were investigated as a catalysts for propane dehydrogenation in the presence of carbon dioxide. Beta zeolite was applied due to a three-dimensional structure, the pores larger than those of ZSM- 5 with 12 -membered ring openings ( 0.75 by $0.57 \mathrm{~nm}$ for linear and 0.65 by $0.56 \mathrm{~nm}$ for tortuous channels), a high thermal and acid stability and a large specific surface area needed for high chromium species dispersion [33-35]. We have shown that dealumination of Beta and subsequently chromium dispersion by simple impregnation procedure give excellent catalysts for $\mathrm{CO}_{2}-\mathrm{PDH}$.
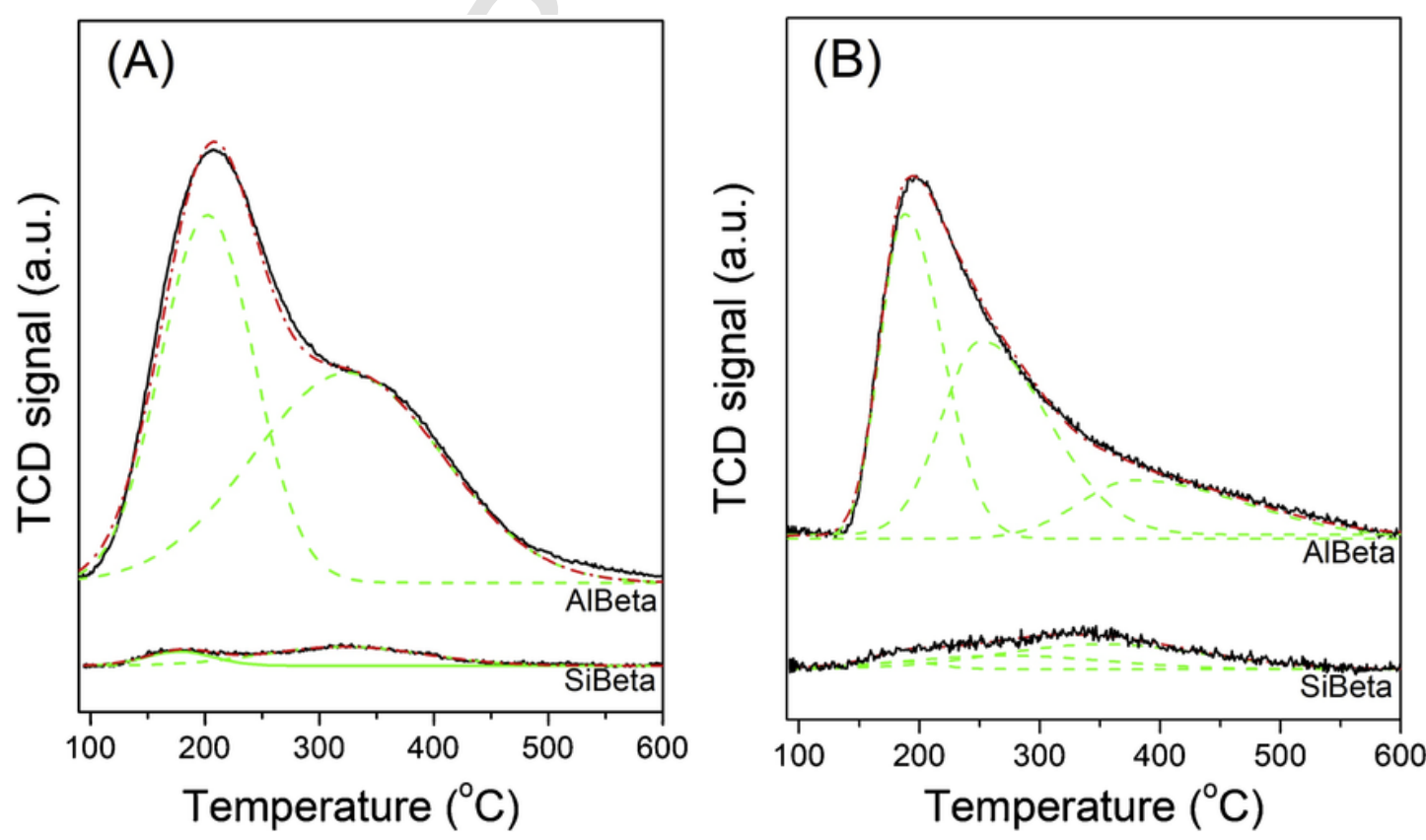

Fig. 2. Thermodesorption profiles of ammonia (A) and carbon dioxide (B) for AlBeta and SiBeta. 

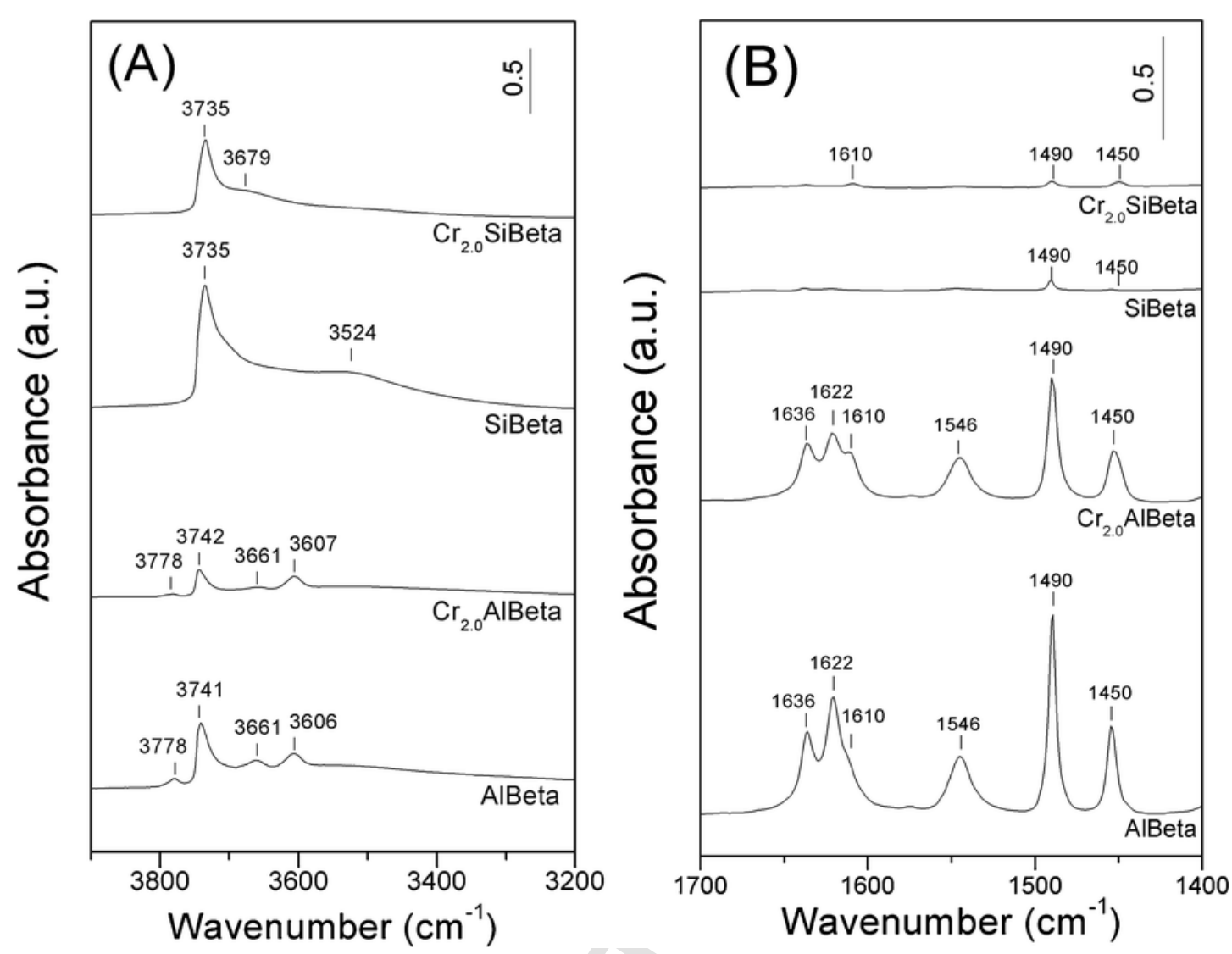

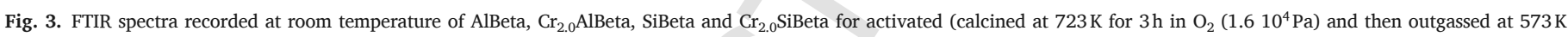
$\left(10^{-3} \mathrm{~Pa}\right)$ for $1 \mathrm{~h}$ ) (Fig. $3 \mathrm{~A}$ ) and after adsorption of pyridine (133 Pa) for $1 \mathrm{~h}$ at room temperature and desorption at $423 \mathrm{~K}$ for 1 (Fig. 3B).

Table 1

Acid-base properties of AlBeta and SiBeta determined by $\mathrm{NH}_{3}$-TPD, pyridine adsorption and $\mathrm{CO}_{2}$-TPD.

\begin{tabular}{|c|c|c|c|c|c|c|c|c|}
\hline \multirow[t]{3}{*}{ Sample } & \multicolumn{5}{|c|}{ Acidity } & \multicolumn{3}{|c|}{ Basicity } \\
\hline & \multicolumn{3}{|c|}{$\mathrm{NH}_{3}$-TPD $\left(\mathrm{mmol} \mathrm{NH}{ }_{3} \cdot \mathrm{g}^{-1}\right)$} & \multicolumn{2}{|c|}{ Pyridine adsorption and desorption at $150^{\circ} \mathrm{C}$ - FTIR } & \multicolumn{3}{|c|}{$\mathrm{CO}_{2}$-TPD $\left(\mathrm{mmol} \mathrm{CO}_{2} \mathrm{~g}^{-1}\right)$} \\
\hline & LT & HT & Total & $\mathrm{PyH}^{+} 1545 \mathrm{~cm}^{-1}\left[\mu \mathrm{molg}^{-1}\right]$ & PyL $1445-1455 \mathrm{~cm}^{-1}\left[\mu \mathrm{molg}^{-1}\right]$ & LT & HT & Total \\
\hline SiBeta & 0.01 & 0.04 & 0.06 & 12 & 10 & 0.01 & 0.01 & 0.02 \\
\hline AlBeta & 0.60 & 0.69 & 1.29 & 235.6 & 134.9 & 0.13 & 0.03 & 0.16 \\
\hline
\end{tabular}

\section{Experimental}

\subsection{Materials preparation}

The AlBeta support with a $\mathrm{Si} / \mathrm{Al}$ atomic ratio of 17 was obtained by calcination of tetraethylammonium Beta (TEABeta) parent zeolite in air at $550^{\circ} \mathrm{C}$ for $15 \mathrm{~h}$. The SiBeta support with a Si/Al atomic ratio of 1000 was obtained by a treatment of TEABeta with $13 \mathrm{~mol} \mathrm{~L}^{-1} \mathrm{HNO}_{3}$ solution at $80^{\circ} \mathrm{C}$ for $4 \mathrm{~h}$, washed with distilled water and dried at $95^{\circ} \mathrm{C}$ overnight.

Chromium-containing SiBeta catalysts were obtained by two-step postsynthesis methodwet impregnation. In typical procedure, the SiBeta was contacted with an aqueous chromium nitrate solutions containing from 0.8 to $15.2 \cdot 10^{-3} \mathrm{~mol} \mathrm{~L}^{-1} \mathrm{Cr}\left(\mathrm{NO}_{3}\right)_{3} \cdot 9 \mathrm{H}_{2} \mathrm{O}$ and AlBeta was contacted with solution containing $3.2 \cdot 10^{-3} \mathrm{~mol} \mathrm{~L}^{-1} \mathrm{Cr}\left(\mathrm{NO}_{3}\right)_{3} \cdot 9 \mathrm{H}_{2} \mathrm{O}$. Then, the separation of the solids from the suspensions were done in evaporator under vacuum of a membrane pump for $2 \mathrm{~h}$ in air at $60^{\circ} \mathrm{C}$. Finally, all materials were calcined at $550^{\circ} \mathrm{C}$ for $6 \mathrm{~h}$. The sample with
SiBeta contained 0.5, 1, 2, 5 and $7 \mathrm{wt} \%$ of $\mathrm{Cr}$ were labelled as $\mathrm{Cr}_{0.5} \mathrm{Si}$ Beta, $\mathrm{Cr}_{1.0} \mathrm{SiBeta}, \mathrm{Cr}_{2.0} \mathrm{SiBeta}, \mathrm{Cr}_{5.0} \mathrm{SiBeta}$ and $\mathrm{Cr}_{7.0} \mathrm{SiBeta}$ and this with AlBeta, containing $2 \mathrm{wt} \%$ of $\mathrm{Cr}$ was labelled as $\mathrm{Cr}_{2.0} \mathrm{AlBeta}$.

\subsection{Materials characterization}

Textural properties of supports and catalysts were determined from the low-temperature adsorption/desorption isotherms using the Micromeritics (ASAP 2020). Priori to measurements the samples were degassed under vacuum at $350^{\circ} \mathrm{C}$ for $12 \mathrm{~h}$. Total pore volume were measured for the value of $\mathrm{p} / \mathrm{p}_{0}=0,98$ and the surface area of the samples were calculated from nitrogen isotherm data using BET and Langmuir models. The micropore volume was determined using the t-plot method.

Powder X-ray diffraction (XRD) analysis of supports and catalysts were performed on a Bruker D8 ADVANCE using $\mathrm{Cu} \mathrm{K}_{\alpha}$ radiation $(\lambda=154,05 \mathrm{pm})$ in $2 \theta$ range of $5-45^{\circ}$.

Analysis of the acidic properties of samples was performed by adsorption of pyridine (Py) followed by infrared spectroscopy. Before analysis, the samples were pressed at $\sim 1$ ton $\mathrm{cm}^{-2}$ into thin wafers of 


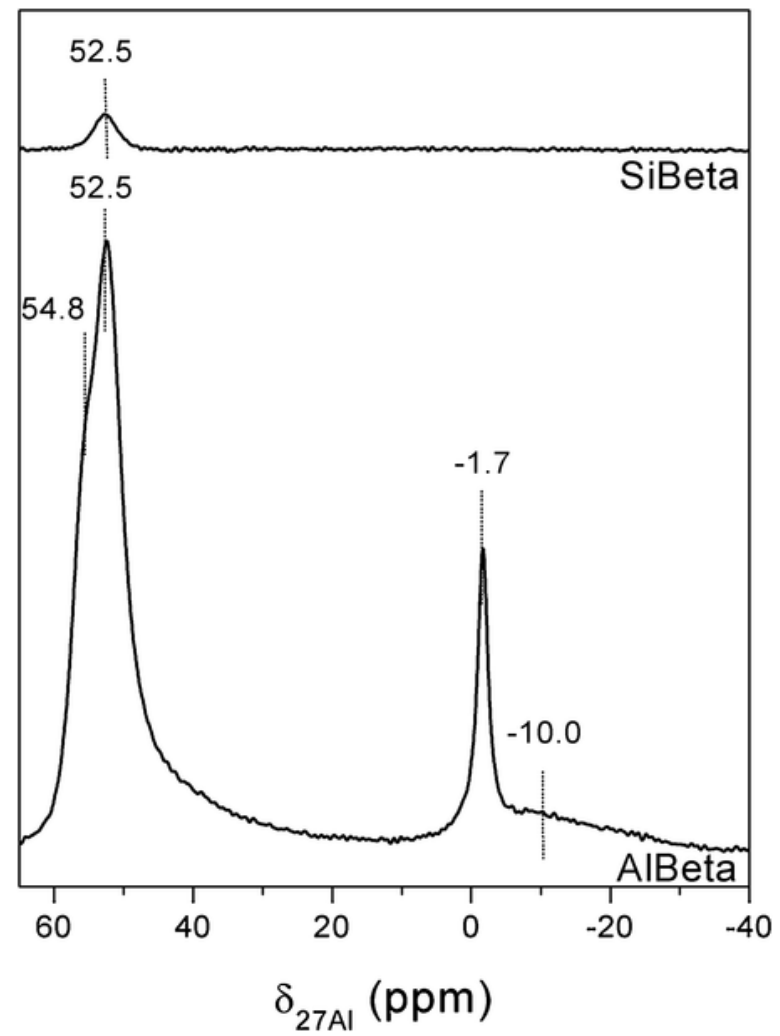

Fig. 4. ${ }^{27} \mathrm{Al}$ MAS NMR recorded at room temperature of AlBeta and SiBeta supports in $4 \mathrm{~mm}$ (external diameter) zirconia rotor.

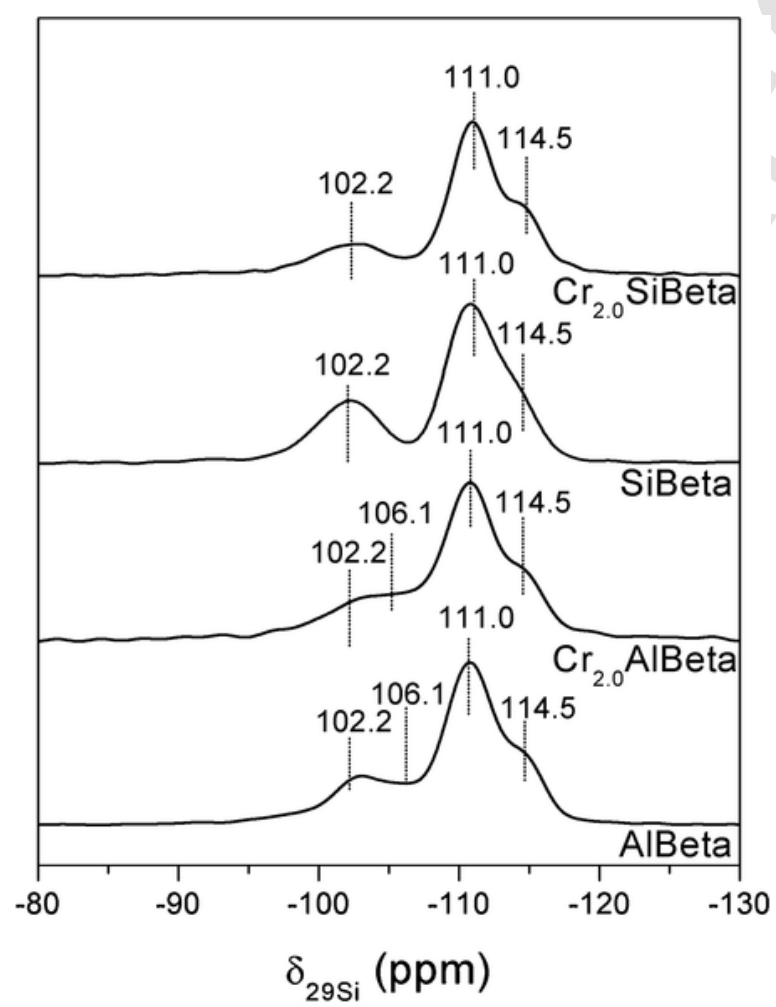

Fig. 5. ${ }^{29} \mathrm{Si}$ MAS NMR recorded at room temperature of AlBeta, $\mathrm{Cr}_{2.0} \mathrm{AlBeta}$, SiBeta and $\mathrm{Cr}_{2.0} \mathrm{SiBeta}$.

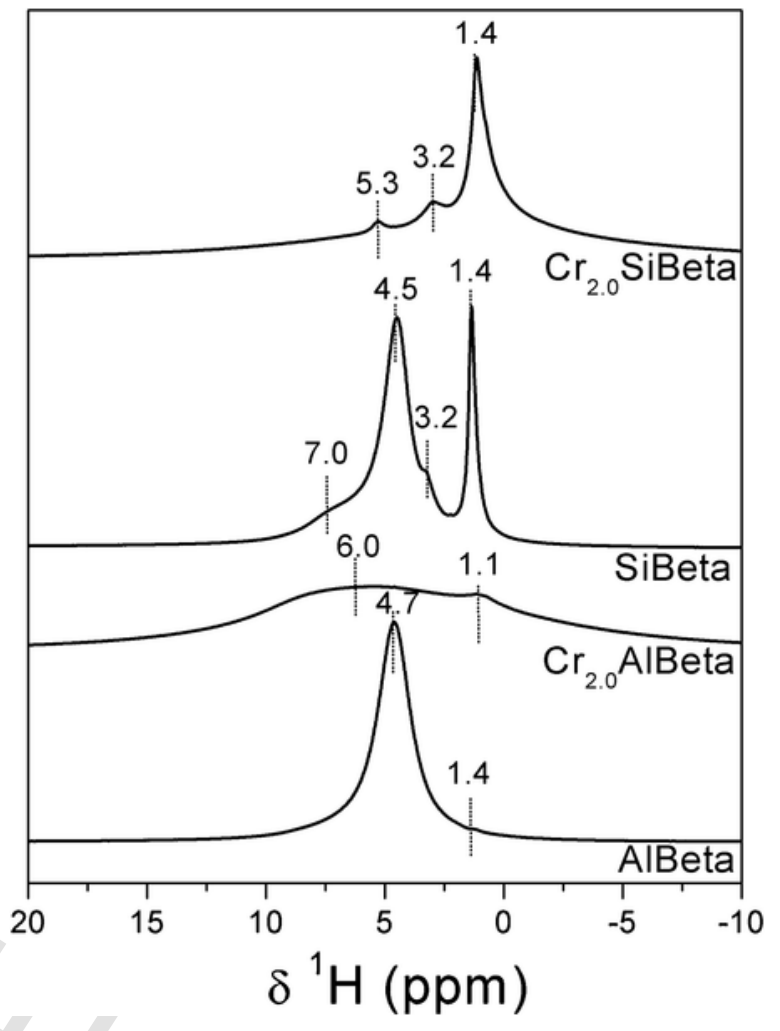

Fig. 6. ${ }^{1} \mathrm{H}$ MAS NMR recorded at room temperature of AlBeta, $\mathrm{Cr}_{2.0} \mathrm{AlBeta}$, SiBeta and $\mathrm{Cr}_{2.0}$ SiBeta.

ca. $10 \mathrm{mg} \mathrm{cm}^{-2}$ and placed inside the IR cell. Then, the wafers were activated by calcination in static conditions at $723 \mathrm{~K}$ for $3 \mathrm{~h}$ in $\mathrm{O}_{2}$ $\left(1.6 \cdot 10^{4} \mathrm{~Pa}\right)$ andoutgassed at $573 \mathrm{~K}\left(10^{-3} \mathrm{~Pa}\right)$ for $1 \mathrm{~h}$. After the wafers were contacted at room temperature with gaseous Py (133Pa). The IR spectra were recorded after desorption at room temperature and $423 \mathrm{~K}$ for $1 \mathrm{~h}$ with a Bruker Vector 22 spectrometer (resolution $2 \mathrm{~cm}^{-1}, 128$ scans). The reported spectra were obtained after subtraction of the spectrum recorded before Py adsorption.

${ }^{29} \mathrm{Si}$ MAS NMR spectra were recorded at $99.3 \mathrm{MHz}$ with Bruker AVANCE 500 spectrometer and $7 \mathrm{~mm}$ zirconia rotors spinning at $5 \mathrm{kHz}$. Tetramethylsilane was used as reference. ${ }^{29} \mathrm{Si}$ MAS NMR spectra were recorded with a $4.2 \mu \mathrm{s}$ excitation pulse and a 10 s recycle delay.

${ }^{27} \mathrm{Al}$ and ${ }^{1} \mathrm{H}$ MAS NMR experiments were performed using a $4 \mathrm{~mm}$ zirconia rotors spinning at $12 \mathrm{kHz}$. The resonance frequency of $500.16 \mathrm{MHz}$ and $130.33 \mathrm{MHz}$ were used for recording of ${ }^{1} \mathrm{H}$ and ${ }^{27} \mathrm{Al}$, respectively. An aqueous $\mathrm{Al}\left(\mathrm{NO}_{3}\right)_{3} 1 \mathrm{~N}$ solution was used as second reference to determine chemical shifts. ${ }^{1} \mathrm{H}$ MAS NMR was recorded with a $90^{\circ}$ pulse duration of $2.9 \mu \mathrm{s}$ and a recycle delay of $5 \mathrm{~s}$ and 16 accumulations. A small-flip-angle technique with a pulse of $1.2 \mu \mathrm{s}(\pi / 8), 0.5 \mathrm{~s}$ for the recycle delay and 2048 accumulations was used for recorded ${ }^{27} \mathrm{Al}$ MAS NMR.

The total $\mathrm{Cr}$ content $\left(\mathrm{Cr}_{\mathrm{ICP}}\right)$ in the samples was determined using an Optima 2100 DV (Perkin-Elmer, USA) ICP-OES instrument, equipped with axially viewed plasma. In the typical mineralization procedure, a sample (ca. $50 \mathrm{mg}$ ) was crashed and mixed with $2 \mathrm{~g}$ of $\mathrm{NaNO}_{3}$ (POCh-Polish Chemical Reagents) and $2 \mathrm{~g}$ of $\mathrm{NaOH}$ (POCh-Polish Chemical Reagents) in a melting pot. Then, the mixture was heated to $600{ }^{\circ} \mathrm{C}$ in air. The mineralization mixture was cooled to RT, dissolved in deionized water and filtered. $\mathrm{Cr}_{\mathrm{ICP}}$ was determined in a dissolved solution.

Temperature-programmed desorption of ammonia $\left(\mathrm{NH}_{3}-\mathrm{TPD}\right)$ and reduction with hydrogen $\left(\mathrm{H}_{2}\right.$-TPR) experiments were carried out using microreactor connected on-line with a GC equipped with a thermal conductivity detector. In $\mathrm{NH}_{3}$-TPD measurements about $0.1 \mathrm{~g}$ sample 
Table 2

$\mathrm{Cr}$ content, specific surface area, porosity and redox properties of $\mathrm{Cr}_{\mathrm{X}} \mathrm{SiBeta}$ catalysts.

\begin{tabular}{|c|c|c|c|c|c|c|c|}
\hline Sample & $\mathrm{Cr}_{\mathrm{ICP}}$ content (wt \%) & $\mathrm{S}_{\mathrm{BET}}\left(\mathrm{m}^{2} \mathrm{~g}^{-1}\right)$ & $\mathrm{S}_{\text {Langmuir }}\left(\mathrm{m}^{2} \mathrm{~g}^{-1}\right)$ & $\mathrm{V}_{\text {micro }}\left(\mathrm{cm}^{3} \mathrm{~g}^{-1}\right)$ & $\mathrm{V}_{\text {total }}\left(\mathrm{cm}^{3} \mathrm{~g}^{-1}\right)$ & $\mathrm{H}_{2}$-TPR & \\
\hline & & & & & & $\mathrm{H}_{2}$ consumption (mmol g ${ }_{\text {cat }}{ }^{-1}$ ) & $\mathrm{H}_{2} / \mathrm{Cr}_{\mathrm{ICP}}(\mathrm{mol} / \mathrm{mol})$ \\
\hline $\mathrm{Cr}_{0.5} \mathrm{SiBeta}$ & 0.55 & 627 & 724 & 0.22 & 0.42 & 0.13 & 1.46 \\
\hline $\mathrm{Cr}_{1.0} \mathrm{SiBeta}$ & 1.15 & 621 & 713 & 0.20 & 0.41 & 0.23 & 1.34 \\
\hline $\mathrm{Cr}_{2.0}$ SiBeta & 2.14 & 554 & 644 & 0.16 & 0.34 & 0.42 & 1.14 \\
\hline $\mathrm{Cr}_{5.0} \mathrm{SiBeta}$ & 4.96 & 552 & 640 & 0.19 & 0.37 & 0.73 & 0.84 \\
\hline $\mathrm{Cr}_{7.0} \mathrm{SiBeta}$ & 6.40 & 517 & 597 & 0.17 & 0.35 & 1.18 & 0.81 \\
\hline $\mathrm{Cr}_{2.0} \mathrm{AlBeta}$ & 2.20 & 618 & 713 & 0.20 & 0.41 & 0.46 & 1.18 \\
\hline
\end{tabular}
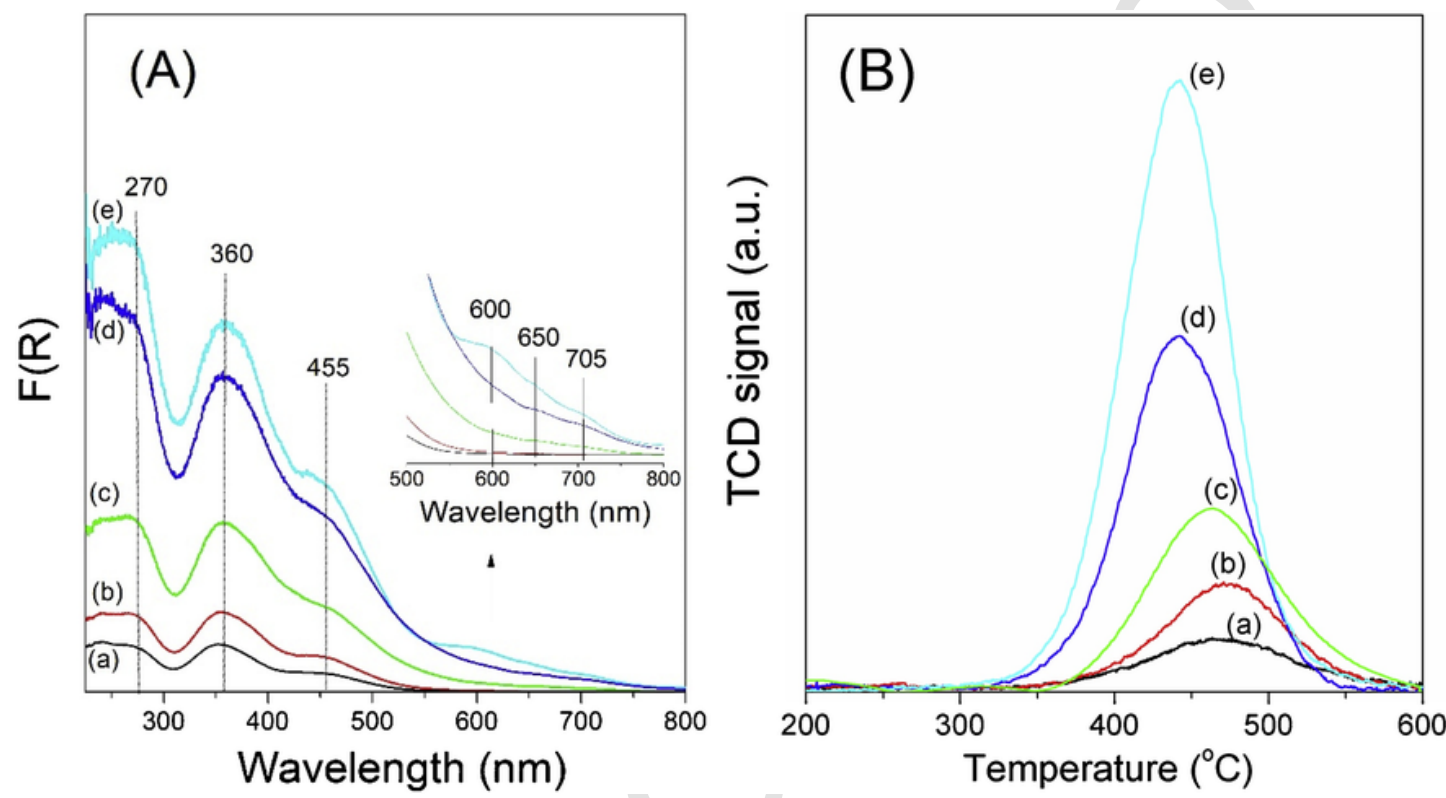

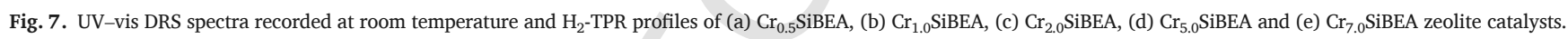

Table 3

Catalytic performance of chromium-containing Beta catalysts and other supported chromium oxide-based catalysts in $\mathrm{CO}_{2}-\mathrm{PDH}$ process.

\begin{tabular}{|c|c|c|c|c|c|c|c|c|c|c|}
\hline \multirow[t]{2}{*}{ Sample } & \multirow[t]{2}{*}{ Reaction temperature } & \multirow[t]{2}{*}{ Specific activity $\times 10^{6}\left(\mathrm{~mol} \mathrm{~s}^{-1} \mathrm{~g}_{\text {cat }}{ }^{-1}\right)$} & \multicolumn{2}{|c|}{ Conversion (\%) } & \multirow{2}{*}{$\begin{array}{l}\text { Yield (\%) } \\
\mathrm{C}_{3} \mathrm{H}_{6}\end{array}$} & \multicolumn{2}{|c|}{ Selectivity (\%) } & \multirow[b]{2}{*}{$\mathrm{C}_{2} \mathrm{H}_{4}$} & \multirow[b]{2}{*}{$\mathrm{CH}_{4}$} & \multirow[t]{2}{*}{ References } \\
\hline & & & $\mathrm{C}_{3} \mathrm{H}_{8}$ & $\mathrm{CO}_{2}$ & & $\mathrm{C}_{3} \mathrm{H}_{6}$ & $\mathrm{C}_{2} \mathrm{H}_{6}$ & & & \\
\hline $\mathrm{Cr}_{0.5} \mathrm{SiBeta}$ & 550 & 0.82 & 11.0 & 0.6 & 10.1 & 94.7 & 1.5 & 3.6 & 2.8 & This work ${ }^{\mathrm{a}}$ \\
\hline $\mathrm{Cr}_{1.0} \mathrm{SiBeta}$ & 550 & 1.31 & 17.6 & 1.2 & 16.0 & 90.8 & 1.4 & 4.5 & 3.3 & \\
\hline $\mathrm{Cr}_{2.0} \mathrm{SiBeta}$ & 550 & 1.85 & 24.8 & 4.0 & 21.6 & 87.1 & 2.4 & 4.2 & 6.2 & \\
\hline $\mathrm{Cr}_{5.0}^{2.0} \mathrm{SiBeta}$ & 550 & 2.05 & 27.6 & 5.5 & 23.3 & 84.4 & 2.8 & 4.0 & 8.8 & \\
\hline $\mathrm{Cr}_{7.0} \mathrm{SiBeta}$ & 550 & 2.48 & 33.3 & 7.0 & 27.2 & 81.6 & 3.7 & 4.0 & 10.7 & \\
\hline $\mathrm{Cr}_{2.0} \mathrm{AlBeta}$ & 550 & 0.33 & 4.5 & 0.8 & 2.0 & 45.1 & 8.0 & 25 & 21.9 & \\
\hline $\mathrm{Cr}_{5.0} / \mathrm{AC}^{\mathrm{b}}$ & 550 & n.r..$^{c}$ & 39.8 & n.r. & 34.5 & 86.7 & 1.6 & 2.8 & 7.5 & {$[32]$} \\
\hline $\mathrm{Cr}_{3.4} / \mathrm{D}^{\mathrm{d}}$ & 600 & n.r. & 19.7 & n.r. & 11.8 & 59.6 & $7.3^{\mathrm{e}}$ & & 5.4 & [7] \\
\hline $\mathrm{Cr}_{3.4} / \mathrm{Al}_{2} \mathrm{O}_{3}$ & 550 & n.r. & 3.3 & n.r. & 3.3 & 92.9 & 0.5 & 1.6 & 5.0 & [5] \\
\hline $\mathrm{Cr}_{3.4} / \mathrm{SiO}_{2}$ & 550 & 1.6 & 15.4 & 1.3 & 14.3 & 92.6 & 1.3 & 2.5 & 3.6 & {$[28]$} \\
\hline $\mathrm{Cr}_{5.0} / \mathrm{ZrO}_{2}$ & 550 & n.r. & 58 & 42 & 30 & n.r. & & & & {$[60]$} \\
\hline $\mathrm{Cr}_{3.4} / \mathrm{MCM}-41$ & 600 & n.r. & 39.4 & 6.7 & 34.9 & 88.5 & 2.9 & 2.5 & 6.1 & [14] \\
\hline $\mathrm{Cr}_{\mathrm{x}} / \mathrm{ZSM}-5-\mathrm{S}$ & 550 & n.r. & 48.3 & n.r. & 41.5 & 86.0 & 2.0 & 4.8 & 7.2 & [61] \\
\hline $\mathrm{Cr}_{3.4} / \mathrm{SBA}-1$ & 550 & 2.60 & 33.2 & 4.6 & 29.2 & 87.9 & 2.9 & 3.3 & 5.9 & {$[28]$} \\
\hline $\mathrm{Cr}_{3.4} / \mathrm{SBA}-15$ & 550 & 2.20 & 27.2 & 3.4 & 24.3 & 89.3 & 2.4 & 3.5 & 4.7 & {$[28]$} \\
\hline $\mathrm{Cr}_{5.0} / \mathrm{MSUx}$ & 600 & n.r. & 28.0 & n.r. & 26.6 & 95.0 & n.r. & n.r. & n.r. & [15] \\
\hline
\end{tabular}

a Reaction conditions: $\mathrm{C}_{3} \mathrm{H}_{8}: \mathrm{CO}_{2}:$ He molar ratio $=1: 5: 9$; Total flow rate $=30 \mathrm{~cm}^{3} \mathrm{~min}^{-1}$; Catalyst weight $=200 \mathrm{mg}$; WHSV $=1.2 \mathrm{~h}-1$; Catalytic test results summarized after $10 \mathrm{~min}$.

b AC- activated carbon.

c n.r.- not reported.

d D- diamond.

e Sum of ethane and ethene selectivity.

(mixed with $\mathrm{SiC}$ to constant volume $1,5 \mathrm{~mL}$ ) was preheated under helium (99.999vol \%, Linde) with heating rate $10^{\circ} \mathrm{Cmin}^{-1}$ to $550{ }^{\circ} \mathrm{C}$, kept for $2 \mathrm{~h}$, and then cooled to $100^{\circ} \mathrm{C}$ under the same atmosphere.
Subsequently, ammonia ( $99.98 \mathrm{vol} \%$, Linde) at flow rate $20 \mathrm{mLmin}^{-1}$ for $30 \mathrm{~min}$ were adsorbed at $100^{\circ} \mathrm{C}$. The sample was then flashed by helium at a flow rate $30 \mathrm{~mL} \mathrm{~min}^{-1}$ for $2 \mathrm{~h}$. The $\mathrm{NH}_{3}$-TPD measurement 


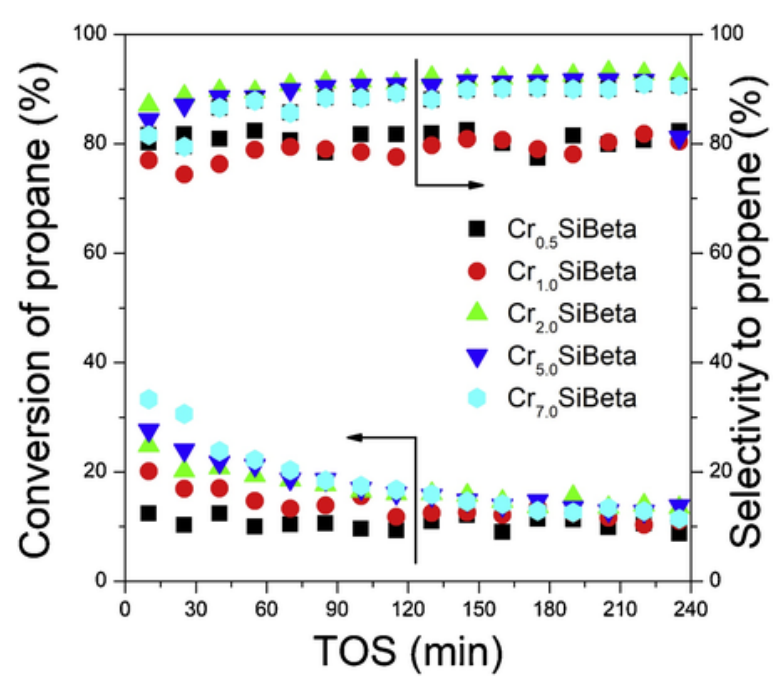

Fig. 8. Conversion of propane and selectivity to propene vs. TOS in $\mathrm{CO}_{2}-\mathrm{PDH}$ process over $\mathrm{Cr}_{\mathrm{X}} \mathrm{SiBeta}$ series. Reaction conditions: $\mathrm{T}=550^{\circ} \mathrm{C} ; \mathrm{C}_{3} \mathrm{H}_{8}: \mathrm{CO}_{2}: \mathrm{He}$ molar ratio = 1:5:9; Total flow rate $=30 \mathrm{~cm}^{3} \mathrm{~min}^{-1}$; Catalyst weight $=200 \mathrm{mg}$; WHSV $=1.2 \mathrm{~h}^{-1}$.

was conducted by heating the sample from $100^{\circ} \mathrm{C}$ to $800^{\circ} \mathrm{C}$ with the heating rate of $10^{\circ} \mathrm{Cmin}^{-1}$.

In $\mathrm{H}_{2}$-TPR experiments $0.1 \mathrm{~g}$ of sample dilute with $\mathrm{SiC}$ was first preheated in air flow for $30 \mathrm{~min}$ at $550^{\circ} \mathrm{C}$ and then in dry $\mathrm{He}$ ( 99.999 vol. \%, Linde,) stream for next $30 \mathrm{~min}$. After that the sample was cooled down in the He stream to $100^{\circ} \mathrm{C}$. The $\mathrm{H}_{2}$-TPR analysis was then performed using mixture of $\mathrm{N}_{2} / \mathrm{H}_{2}(95 / 5 \mathrm{vol}$. \%, Air Liquide) environment at a total flow rate $30 \mathrm{~mL} \mathrm{~min}^{-1}$ and ramped from 100 to $650^{\circ} \mathrm{C}$ with heating rate of $10^{\circ} \mathrm{Cmin}^{-1}$. The $\mathrm{H}_{2}$ consumption was mea-
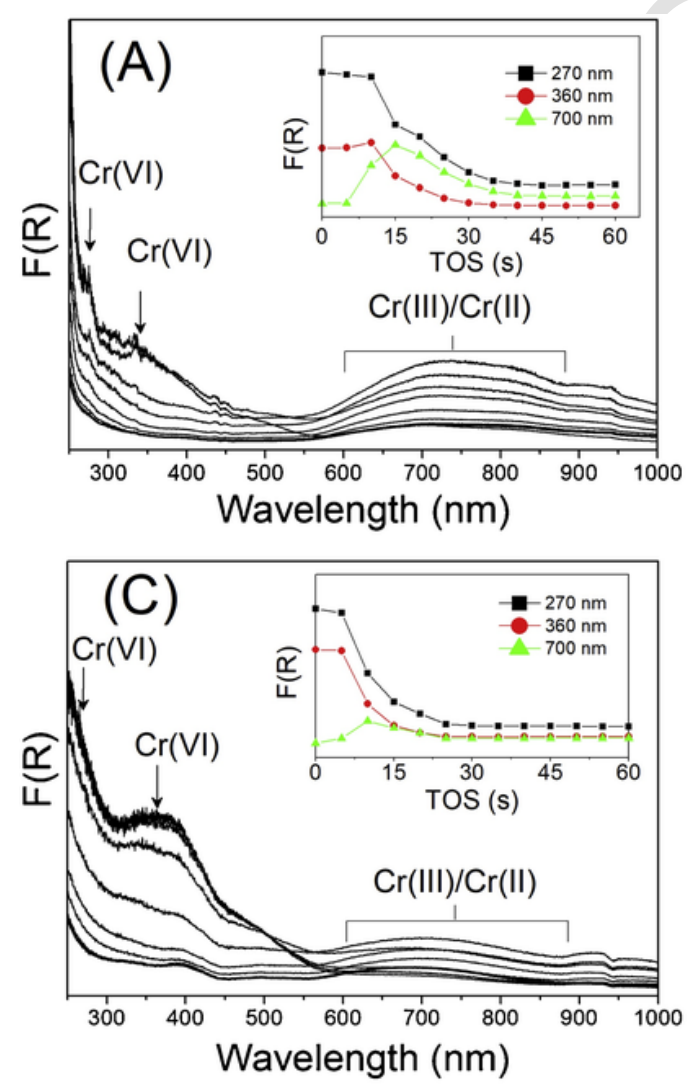

sured using TCD and NiO (99.999\%, Aldrich) was used as a reference for the calibration of $\mathrm{H}_{2}$ consumption.

Diffuse reflectance UV-vis analysis was conducted using an Ocean Optics HR2000 + spectrometer (integration time $50 \mathrm{~ms}$, 50 scans) equipped with an DH-2000 BAL halogen-deuterium light source. The spectra were recorded between 225 to $800 \mathrm{~nm}$ and barium sulfate $(99 \%$ Sigma-Aldrich) was use as a standard.

During selected catalytic tests carried out at $550{ }^{\circ} \mathrm{C}$ experiments with the oxidation state of chromium species was monitored using UV-vis equipment mentioned above (integration time $25 \mathrm{~ms}$, 25scans) and a high temperature reflection probe (FCR-7UV400-2-ME-HTX, $7 \times 400 \mu \mathrm{m}$ fibers). The probe was attached at the top of quartz microreactor within the distance of $2-3 \mathrm{~mm}$ from catalyst bed.

\subsection{Catalyst evaluation}

$\mathrm{CO}_{2}$-PDH reaction was carried out in a flow-type quartz reactor. Typically, $0.2 \mathrm{~g}$ of the catalyst (grain size $0.2-0.3 \mathrm{~mm}$ ) was preheated in a stream of dry helium (99.999vol. \%, Linde) for $30 \mathrm{~min}$ at $550^{\circ} \mathrm{C}$ before each catalytic measurements, and then the reaction was started at $550^{\circ} \mathrm{C}$ under atmospheric pressure. The feed consisted of a mixture of propane ( $99.96 \mathrm{vol} \%$, Linde) and $\mathrm{CO}_{2}(99.996 \mathrm{vol} \%$, Linde) diluted with helium. The volumetric ratio of $\mathrm{CO}_{2} / \mathrm{C}_{3} \mathrm{H}_{8} / \mathrm{He}=5 / 1 / 9$ was introduced into the reactor at a flow rate of $30 \mathrm{~mL} \mathrm{~min}^{-1}$. In reference catalytic test without $\mathrm{CO}_{2}$ (non-oxidative dehydrogenation) the volumetric ratio of $\mathrm{C}_{3} \mathrm{H}_{8} / \mathrm{He}=1 / 14$ was used.

The composition of the reactor exhaust was analyzed by gas chromatograph (Agilent $6890 \mathrm{~N}$ ) which was equipped with a thermal conductivity detector, Hayesep $\mathrm{Q}$ and molecular sieve $5 \mathrm{~A}$ columns. $\mathrm{H}_{2}$, $\mathrm{CO}_{2}, \mathrm{C}_{2} \mathrm{H}_{4}, \mathrm{C}_{2} \mathrm{H}_{6}, \mathrm{C}_{3} \mathrm{H}_{6}$ and $\mathrm{C}_{3} \mathrm{H}_{8}$ were separated by Hayesep $\mathrm{Q}$ column
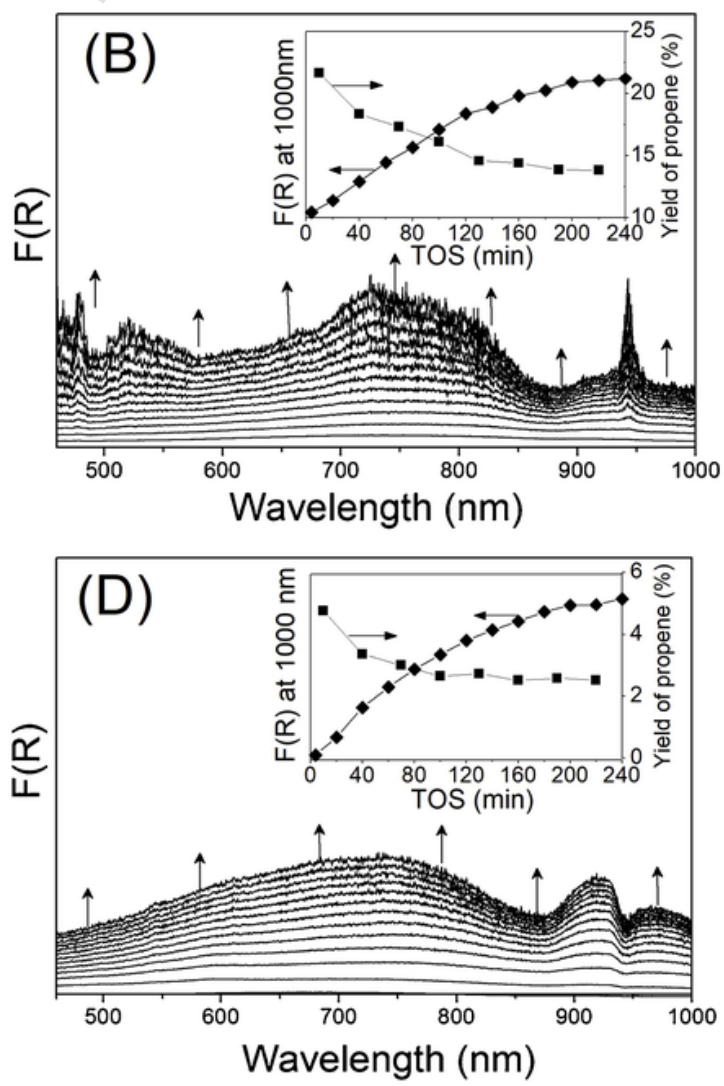

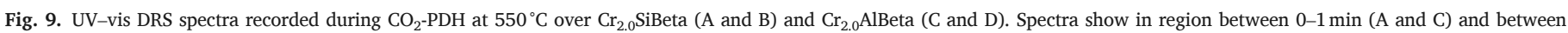
$1-240 \mathrm{~min}$ (B and D) in interval $5 \mathrm{~s}$. and $10 \mathrm{~min}$, respectively. 


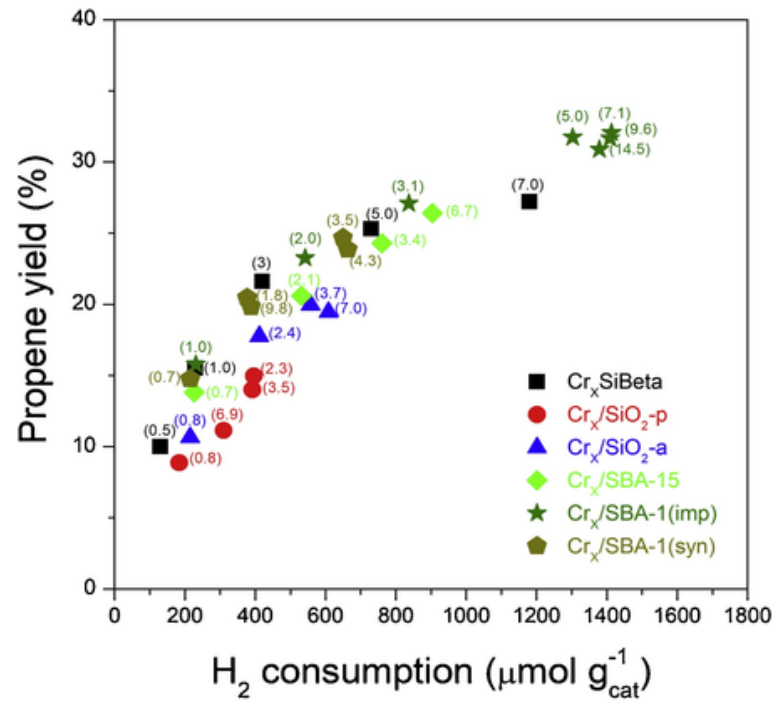

Fig. 10. The variation of propene yield with hydrogen consumption (proportional to number of $\mathrm{Cr}$ redox species) for several different chromium oxide based catalysts. Hydrogen consumption was calculated per catalysts weight based on $\mathrm{H}_{2}$-TPR experiments. Sample notations: $\mathrm{Cr}_{\mathrm{x}} / \mathrm{SBA}-1$ (imp), $\mathrm{Cr}_{\mathrm{x}} / \mathrm{SBA}-15, \mathrm{Cr}_{\mathrm{x}} / \mathrm{SiO}_{2}$-a (silica support from Aldrich) and $\mathrm{Cr}_{\mathrm{x}} / \mathrm{SiO}_{2}$-p (silica support from Polish Chemical Reagents) catalysts obtained by impregnation [28]; $\mathrm{Cr}_{\mathrm{x}} / \mathrm{SBA}-1$ (syn) catalyst prepared by $\mathrm{Cr}$ incorporation during SBA-1 synthesis [65]; The values in the brackets indicates total $\mathrm{Cr}$ content in the catalysts.

while $\mathrm{CH}_{4}$ and $\mathrm{CO}$ were separated using column with molecular sieve $5 \mathrm{~A}$.

Activity normalized per catalyst weight (1), conversion of propane (2) and carbon dioxide (3), yield of propene (4) and selectivity to hydrocarbon products (5) were calculated as:

Specific activity (mmol

$$
\left.\cdot s^{-1} \cdot g_{\text {cat. }}^{-1}\right)=F_{C_{3} H_{8}} \cdot C_{C_{3} H_{8}}
$$

Yield of propene $\quad(\%)=\frac{n_{C_{3} H_{6}, \text { outlet }}}{n_{C_{3} H_{8}, \text { inlet }}} \cdot 100 \%$
Conversion of propane (\%)
$=\frac{n_{C_{3} H_{8}, \text { inlet }}-n_{C_{3} H_{8}, \text { outlet }}}{n_{C_{3} H_{8}, \text { inlet }}} \cdot 100 \%$

Conversion of carbon dioxide $=\frac{n_{\mathrm{CO}_{2}, \text { inlet }}-n_{\mathrm{CO}_{2}, \text { outlet }}}{n_{\mathrm{CO}_{2}, \text { inlet }}} \cdot 100 \%$

$(\%)$

Selectivity $(\%)=\frac{\frac{a_{i}}{3} \cdot n_{i}}{n_{C_{3} H_{8}, \text { inlet }}-n_{C_{3} H_{8}, \text { outlet }}} \cdot 100 \%$

where: $F_{C 3 H 8}$, is a number of propane moles per second, $C_{C 3 H 8}$ is conversion of propane per gram of a catalyst $n_{C_{3} H_{8} \text {,inlet }} n_{C_{2} \text {, inlet }}$ and $n_{C_{3} H_{8} \text {,outlet }} n_{\mathrm{CO}_{2} \text {,outlet }}$ are numbers of propane and carbon dioxide moles

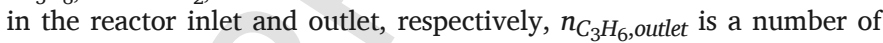
propene moles in the reactor outlet, $a_{i}$ is a number of carbon atoms in a product, and $n_{i}$ is a number of moles of " $i$ " product.

\section{Results and discussion}

\subsection{Support characterization}

Initially, AlBeta $(\mathrm{Si} / \mathrm{Al}=17)$ and SiBeta $(\mathrm{Si} / \mathrm{Al}=1000)$ were characterized for clarify dealumination effect on structure, texture and acid-base properties. As shown in Fig. 1, the crystallinity of Beta zeolite is preserved after dealumination and in the SiBeta support any extra lattice crystalline compounds and long range amorphization do not occur. The increase of 2 theta value of the main diffraction line after dealumination from 22.5 (AlBeta) to $22.7^{\circ}$ (SiBeta) indicates contraction of the Beta matrix, in line with earlier investigations (Fig. 1 inset) [36,37].

Moreover, the dealumination leads to small change in porosity and specific surface area. After $\mathrm{HNO}_{3}$ treatment the BET specific surface area $\left(\mathrm{S}_{\mathrm{BET}}\right)$ increases from $642 \mathrm{~m}^{2} \mathrm{~g}^{-1}$ (AlBeta) to $724 \mathrm{~m}^{2} \mathrm{~g}^{-1}$ (SiBeta) while the total pore volume from $0.52 \mathrm{~cm}^{3} \mathrm{~g}^{-1}$ (AlBeta) to $0.72 \mathrm{~cm}^{3} \mathrm{~g}^{-1}$ (SiBeta) [38]. In contrary to structure and texture changes the dea-
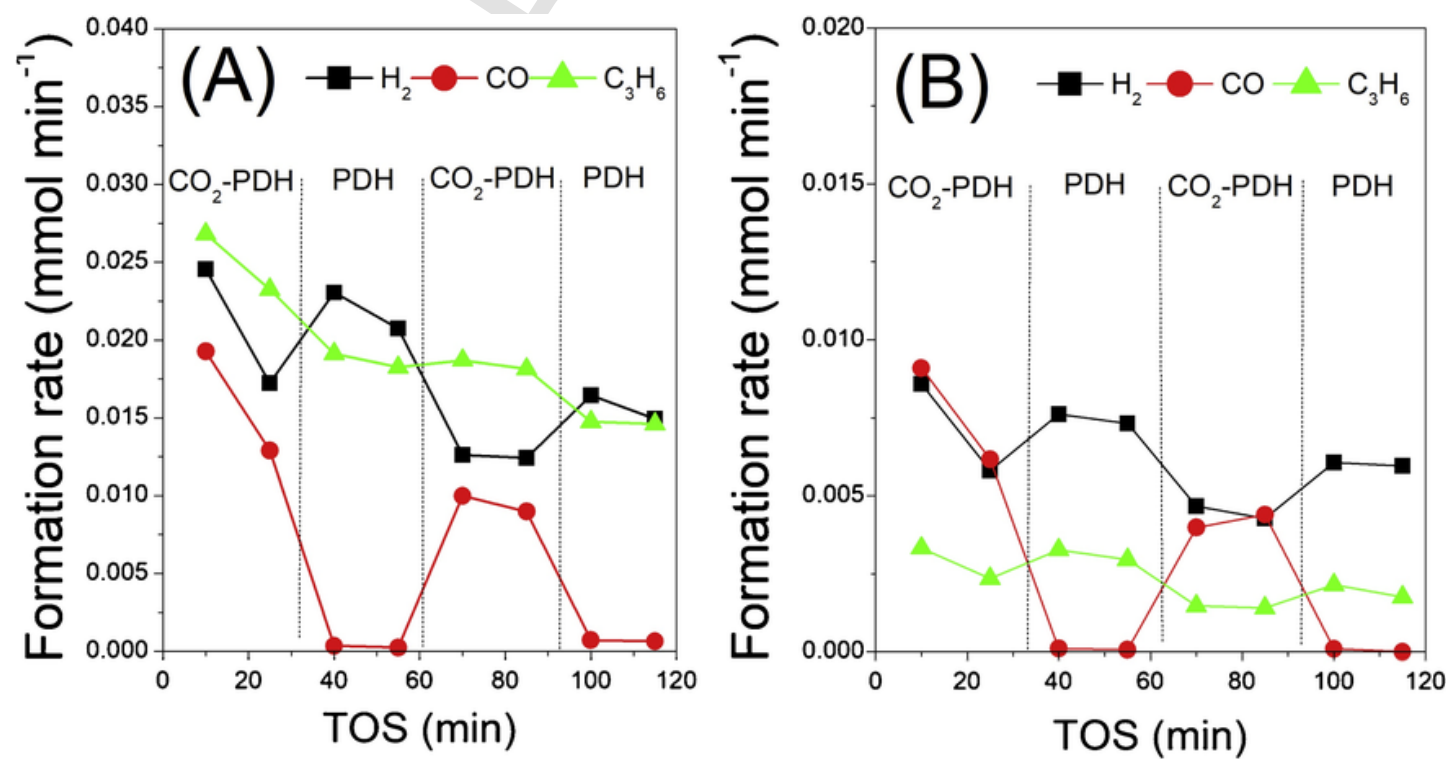

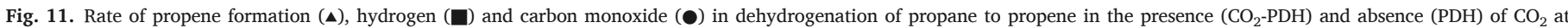
$550^{\circ} \mathrm{C}$ over (A) $\mathrm{Cr}_{2.0}$ SiBeta and (B) $\mathrm{Cr}_{2.0}$ AlBeta catalysts. 


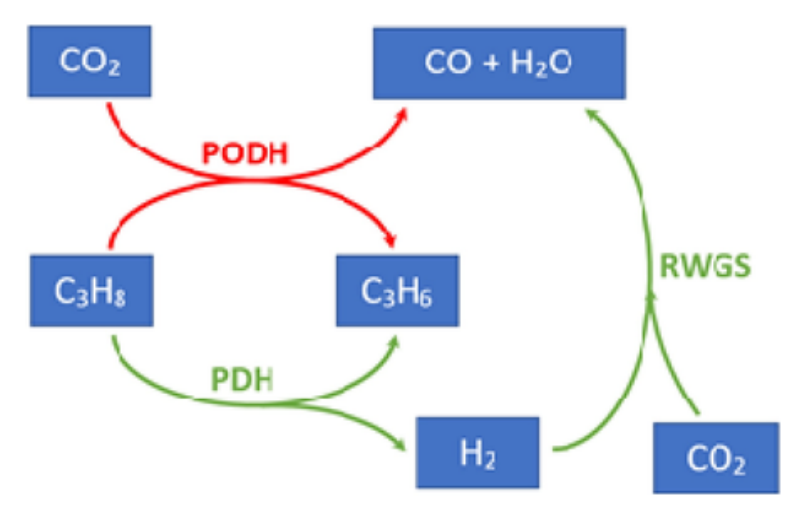

Scheme 1. Possible pathways of propene generation in assistance of $\mathrm{CO}_{2}$ over Cr-containing SiBeta zeolite catalyst. Red arrows - propane oxidative dehydrogenation (PODH); Green arrows: propane dehydrogenation (PDH) coupling with revers water-gas shift (RWGS).

lumination has much significant impact on acidity. The $\mathrm{NH}_{3}$-TPD profiles for AlBeta and SiBeta are compared on Fig. 2A. In both cases two maxima at $200^{\circ} \mathrm{C}$ and $370^{\circ} \mathrm{C}$ are observed on the $\mathrm{NH}_{3}$-TPD profiles suggesting the presence of two type of acid sites, such as Lewis acid sites related to the presence in zeolite structure of $\mathrm{Al}^{3+}$ ions (maximum at around of $200^{\circ} \mathrm{C}$ ) and Bronsted acid sites related to the acidic proton of $\mathrm{Si}-\mathrm{O}(\mathrm{H})-\mathrm{Al}$ groups (maximum at around of $370^{\circ} \mathrm{C}$ ), in agreement with earlier reports $[39,40]$.

However, the intensity of these two peaks on SiBeta profile is much lower than on AlBeta profile indicating clearly that dealumination leads to significant reduction of acid sites number.

Presence of both type acidic sites is confirmed by FTIR investigation with pyridine as probe molecule Fig. 3 .

The treatment of AlBeta zeolite with $\mathrm{HNO}_{3}$ solution involve of elimination of $\mathrm{Al}$ atoms from the framework evidenced by disappearance of IR bands at 3778,3661 and $3606 \mathrm{~cm}^{-1}$ related to $\mathrm{AlO}-\mathrm{H}$ groups (Fig. 3A), in agreement with our earlier investigation [41-43]. The appearance of narrow band at 3735 and shoulder at $3710 \mathrm{~cm}^{-1}$ related to isolated silanol groups and of a broad band at $3524 \mathrm{~cm}^{-1}$ due to $\mathrm{H}$-bonded $\mathrm{SiOH}$ groups in SiBeta reveals the presence of vacant T-atom sites [41,44]. As shown in Table 1, the number of Brønsted and Lewis acid sites decrease strongly when AlBeta zeolite is dealuminated and only traces of Brønsted and Lewis acid sites are detected in SiBeta.

To determine the nature and strength of acidic centres in AlBeta, $\mathrm{Cr}_{2.0}$ AlBeta, SiBeta and $\mathrm{Cr}_{2.0}$ SiBeta zeolite samples, the adsorption of pyridine as probe molecules has been performed. Fig. 3B presents the FTIR spectra of AlBeta, $\mathrm{Cr}_{2.0} \mathrm{AlBeta}$, SiBeta and $\mathrm{Cr}_{2.0} \mathrm{SiBeta}$ after adsorption of pyridine at room temperature and after that desorption by outgassing $1 \mathrm{~h}$ under vacuum of $10^{-3} \mathrm{~Pa}$ at $150^{\circ} \mathrm{C}$. The several IR bands at $1637,1622,1610,1546,1490$, and $1450 \mathrm{~cm}^{-1}$ are observed for AlBeta related to Bronsted acidic centres (the bands at 1637 and $1546 \mathrm{~cm}^{-1}$ ), Lewis acidic centres (the bands at 1622, 1610 and $1450 \mathrm{~cm}^{-1}$ ), Brønsted and Lewis acidic centres (the band at $1490 \mathrm{~cm}^{-1}$ ). The bands typical of pyridinium cations are seen at 1545 and $1637 \mathrm{~cm}^{-1}$, indicating the presence of Brønsted acidic centres related to the acidic proton of $\mathrm{Al}-\mathrm{O}(\mathrm{H})$ - Si groups, in line with earlier data [45]. The bans at $1450 \mathrm{~cm}^{-1}$ correspond to pyridine interacting with strong Lewis acidic centres $\left(\mathrm{Al}^{3+}\right)$. The band at $1490 \mathrm{~cm}^{-1}$ corresponds to pyridine interacting with both Brønsted and Lewis acidic centres.

The ${ }^{27} \mathrm{Al}$ MAS NMR of AlBeta zeolite posses 4 resonances (Fig. 4). The signals at 54.8 and $52.5 \mathrm{ppm}$ associated to aluminum atoms present in two types of the tetrahedral environment of the framework. The signals at -1.7 and $-10 \mathrm{ppm}$ correspond to aluminum atoms in two types of octahedral environment. The first narrow peak, could be attributed to aluminum atoms in a tetrahedral environment near water molecules and the second a large peak could be attributed to ex- traframework species. Due to dealumination, the ${ }^{27} \mathrm{Al}$ NMR spectrum of SiBeta zeolite (Fig. 4) present only one a small signal at $-52.5 \mathrm{ppm}$ corresponding to aluminum atoms in the framework of zeolite [46,47].

The ${ }^{29} \mathrm{Si}$ MAS NMR spectrum of AlBeta (Fig. 5) shows two peaks at -114.5 and $-111.0 \mathrm{ppm}$ related to two crystallographic sites of the framework, $\mathrm{Si}$ atom in a $\mathrm{Si}(\mathrm{OSi})_{4}\left(\mathrm{Q}^{4}\right)$ environment. The signals at -102.2 and $-106.1 \mathrm{ppm}$ correspond to two $\mathrm{Q}^{3}$ species, $(\mathrm{OSi})_{3} \mathrm{Si}(\mathrm{OH})$ and $(\mathrm{OSi})_{3} \mathrm{Si}(\mathrm{Al})$ groups, respectively. ${ }^{29} \mathrm{Si}$ MAS NMR spectrum of SiBeta (Fig. 5) is very similar to that of AlBeta. Only the signal at $-106.1 \mathrm{ppm}$ disappeared as a result of dealumination [48].

The ${ }^{1} \mathrm{H}$ MAS NMR of the AlBeta zeolite (Fig. 6) shows a broad signal at $4.7 \mathrm{ppm}$ due to bridging hydroxyl protons ( $\mathrm{Si}(\mathrm{OH}) \mathrm{Al})$. The small signal at 1.37 corresponds to proton of $\mathrm{SiOH}$ groups. In the ${ }^{1} \mathrm{H}$ MAS NMR spectrum of SiBeta (Fig. 6) two main signals at 4.5 and $1.37 \mathrm{ppm}$, related to the protons of hydrogen bonded $\mathrm{Si}-\mathrm{OH}$ groups present at vacant $\mathrm{T}$-atom sites and to the protons of isolated $\mathrm{Si}-\mathrm{OH}$ groups respectively $[49,50]$. Two peaks at 7 and $3.22 \mathrm{ppm}$ are attributed to protons of water molecules and of hydrogen bonded $\mathrm{Si}-\mathrm{OH}$ groups located in a second type of crystallographic site [51].

Moreover, dealumination leads also to significant reduction of basic sites number. The $\mathrm{CO}_{2}$-TPD profiles for both materials are reported on Fig. 2B. In the case of AlBeta one intensive and a broad maximum ca. $200^{\circ} \mathrm{C}$ with high temperature shoulder appeared, confirming presence of weak and medium basic sites which can be assigned to desorption weakly adsorbed $\mathrm{CO}_{2}$ (physisorbed) and decomposition of carbonates like species. In contrast, the amount of $\mathrm{CO}_{2}$ adsorbed on dealuminated support (SiBeta) is much lower than that on parent AlBeta support. Two maxima with very low intensity at about 200 and $350^{\circ} \mathrm{C}$ appear. The quantitative calculation reported in Table 1 indicates that the total amount of $\mathrm{CO}_{2}$ adsorbed on SiBeta is more than 8 times lower than on AlBeta.

\subsection{Catalysts characterization}

Using SiBeta support the series of Cr-containing SiBeta catalysts was prepared by wet impregnation. Based on AlBeta support the $\mathrm{Cr}_{2.0} \mathrm{AlBeta}$ reference catalyst was prepared as well. Base characterization results of SiBeta series are summarized in Table 2.

Chemical analysis confirms good reproducibility of $\mathrm{Cr}$ incorporation in to the Beta zeolite. Both BET and Langmuir specific surface areas as well as total pore volume drops gradually with the total $\mathrm{Cr}$ content indicating that chromium deposition on SiBeta leads to porosity and surface area reduction, simultaneously.

The decrease of the $2 \theta$ value of the narrow main diffraction line around $2 \theta$ of $22.60^{\circ}$ after introduction of $\mathrm{Cr}$ ions (Fig. 1) indicates some expansion of the Beta structure and suggests that the latter are incorporated into lattice sites. The $2 \theta$ value of this diffraction line decreases from 22.71 (SiBeta) to 22.64 ( $\left.\mathrm{Cr}_{0.5} \mathrm{SiBeta}\right), 22.61$ ( $\left.\mathrm{Cr}_{1.0} \mathrm{SiBeta}\right)$ and $22.56^{\circ}\left(\mathrm{Cr}_{2.0} \mathrm{SiBeta}\right)$ which indicates expansion of the matrix after incorporation of chromium ions into framework of SiBeta support. For higher $\mathrm{Cr}$ content, the decreasing of the $2 \theta$ value of this diffraction line is not observed (Fig. 1), so it suggests that for higher amount than $2 \mathrm{Cr}$ wt \% the $\mathrm{Cr}$ ions are introduced in the extra-framework position of the zeolite structure.

In contrast, the same 2 theta value of the main diffraction line at 22.55 for AlBeta and $\mathrm{Cr}_{2.0} \mathrm{AlBeta}$ suggests that upon wet impregnation of AlBeta support with $\mathrm{Cr}\left(\mathrm{NO}_{3}\right)_{3}$ precursor expansion of zeolite matrix do not occurred. It indicates that $\mathrm{Cr}$ ions are introduced in the extra-framework position of Beta structure.

The incorporation of $\mathrm{Cr}$ leading to $\mathrm{Cr}_{0.5} \mathrm{SiBeta}, \mathrm{Cr}_{1.0} \mathrm{SiBeta}$ and $\mathrm{Cr}_{2.0} \mathrm{SiBeta}$ induces a reduction of intensity of the bands of silanol groups, isolated and hydrogen bonded at 3735 and $3524 \mathrm{~cm}^{-1}$ respectively (Fig. 3). Similar change has been observed for incorporation of vanadium and cobalt ions into SiBeta suggesting that silanol groups are 
consumed in the reaction with chromium nitrate and $\mathrm{Cr}$ ions are simultaneously incorporated into framework of Beta zeolite, in agreement with later reports [41,44]. In addition, introduction of $\mathrm{Cr}$ ions in the AlBeta support leads to decreasing of Brønsted acid sites from $235.6 \mu \mathrm{mol} \mathrm{g}^{-1}$ for AlBeta to $227.3 \mu \mathrm{mol} \mathrm{g}^{-1} \mathrm{Cr}_{2.0} \mathrm{AlBeta}$ and Lewis acid sites from $134.8 \mu \mathrm{molg}^{-1}$ for AlBeta to $126.4 \mu \mathrm{molg}^{-1}$ for $\mathrm{Cr}_{2.0} \mathrm{AlBeta}$. For SiBeta and $\mathrm{Cr}_{2.0}$ SiBeta only traces of Brønsted and Lewis acid sites are observed.

The incorporation of chromium in SiBeta and AlBeta causes a decrease in the signal corresponding to the $(\mathrm{OSi})_{3} \mathrm{Si}(\mathrm{OH})$ group $(-102.2 \mathrm{ppm})$, which suggests an interaction between the chromium and the silanols of the zeolite (Fig. 5). The effect is much more important on $\mathrm{Cr}_{2.0}$ SiBeta than on $\mathrm{Cr}_{2.0} \mathrm{AlBeta}$.

In presence of chromium, the signals of bridging hydroxyl protons in AlBeta $(4.7 \mathrm{ppm}$ ) and the signal of $\mathrm{H}$-bonded $\mathrm{Si}-\mathrm{OH}$ groups present at vacant T-atom sites in SiBeta $(4.5 \mathrm{ppm})$ are very disturbed (Fig. 6). These modifications are due to the paramagnetic properties of chromium, which indicates a proximity between the species.

Furthermore, an oxidation state of chromium species in fresh samples was monitored using UV-vis diffuse reflectance spectroscopy (UV-vis DRS). Fig. 7A summarizes the spectra recorded in the range of 225-800 nm that is characteristic for charge transfer (CT) and d-d transition of chromium species. In all cases, in the CT transition region two peaks at $270 \mathrm{~nm}$ and $360 \mathrm{~nm}$ are detected. These peaks are assigned to CT of $\mathrm{Cr}^{6+}-\mathrm{O}^{2-}$ transition in monochromate species attached with support $[52,53]$. In the case of catalysts with 5 or higher wt $\%$ of $\mathrm{Cr}$ an additional bands with low intensity in d-d region appeared (Fig. 7A). These two bands are characteristic for spin-allowed d-d transitions of $\mathrm{Cr}^{3+}$ [52-55]. Moreover, the band at $600 \mathrm{~nm}$ is asymmetric and has two low energy shoulders ca. $650 \mathrm{~nm}$ and $705 \mathrm{~nm}$, which are assigned to spin-forbidden transition of Cr(III) (inset to Fig. 7A) [43]. The UV-vis DRS results indicate that below $5 \mathrm{wt} \%$ of $\mathrm{Cr}_{\text {total }}$ on SiBeta surface predominate $\mathrm{Cr}(\mathrm{VI})$ species while at and above this content $\mathrm{Cr}(\mathrm{VI})$ and $\mathrm{Cr}(\mathrm{III})$ species coexists.

Presence of $\mathrm{Cr}(\mathrm{VI})$ species in fresh samples is confirmed by $\mathrm{H}_{2}$-TPR experiments (Fig. 7B). In all cases a single reduction maximum between 450 to $470^{\circ} \mathrm{C}$ was observed. This maximum is assigned to reduction of $\mathrm{Cr}(\mathrm{VI})$ to $\mathrm{Cr}(\mathrm{III})$ species [54-56]. However, over ordered and unordered silica supports a deeper reduction of $\operatorname{Cr}(\mathrm{VI})$ to $\mathrm{Cr}(\mathrm{II})$ may also occur [27,28,56-58].

Quantitative results of $\mathrm{H}_{2}$-TPR (Table 2) reveal that the hydrogen consumption rises with the $\mathrm{Cr}_{\text {total }}$ content indicating systematic rises of redox $\mathrm{Cr}(\mathrm{VI})$ species concentration. However, the ratio of $\mathrm{H}_{2} / \mathrm{Cr}_{\text {total }}$ drops from 1.46 to 0.81 as $\mathrm{Cr}$ content rise from 0.5 to $7 \mathrm{wt} \%$ suggesting that with $\mathrm{Cr}_{\text {total }}$ content rises faster contribution of non redox $\mathrm{Cr}$ species (mainly $\mathrm{Cr}_{2} \mathrm{O}_{3}$ amorphous and crystalline) than redox ones. UV-vis DRS results (Fig. 6A) confirm that above 2 wt \% rise the intensity of the d-d transition bands characteristic of $\mathrm{Cr}(\mathrm{III})$ species which are non-redox in nature while XRD indicates $\alpha-\mathrm{Cr}_{2} \mathrm{O}_{3}$ formation above $5 \mathrm{wt} \%$ of $\mathrm{Cr}$ (Fig. $1)$.

\subsection{Catalytic performance}

Initially, the catalytic performances of all materials was investigated in $\mathrm{CO}_{2}-\mathrm{PDH}$ process at $550^{\circ} \mathrm{C}$. Table 3 summarized initial specific activity, propane and carbon dioxide conversion as well as propene yield and selectivity to hydrocarbon products. The catalytic results for reference $\mathrm{Cr}_{2.0} \mathrm{AlBeta}$ catalyst and several others Cr-based materials reported in literature are summarized as well.

It is clear from Table 3 that $\mathrm{Cr}_{\mathrm{x}}$ SiBeta exhibits high catalytic performance, similar to other well know chromium oxide-based system supported on mesoporous silica supports (SBA-1, SBA-15, MCM-41, MSU-x) or active carbon. In $\mathrm{Cr}_{\mathrm{x}} \mathrm{SiBeta}$ series maximum initial yield $27.2 \%$ was obtained on the sample with $7 \mathrm{wt} \%$ of $\mathrm{Cr}$.
Moreover, it is clear that dealumination significantly improve both activity and selectivity. In the case of $\mathrm{Cr}_{2.0}$ AlBeta reference catalyst, the low selectivity to propylene is due to high concentration of strong acid sites over AlBeta support which prefer cracking of propane. Thus, over $\mathrm{Cr}_{2.0}$ AlBeta in product predominates methane, ethane and ethene produced in cracking reaction.

The variation of propane conversion and selectivity to propene vs. time-on-stream (TOS) are summarized in Fig. 8. Over all materials investigated conversion of propane drops with TOS, slightly for Cr-containing SiBeta zeolite with low $\mathrm{Cr}$ content $\left(\mathrm{Cr}_{0.5} \mathrm{SiBeta}\right.$ and $\left.\mathrm{Cr}_{1.0} \mathrm{SiBeta}\right)$ and much significantly for Cr-containing SiBeta zeolite with higher $\mathrm{Cr}$ content (higher than $2 \mathrm{Cr} w \mathrm{wt}$ ). The selectivity to propene variation has opposite trend than propane conversion. It is also clear that in all cases the deactivation has not monotonic trend. It is faster at the beginning of the process and slow down with TOS.

To clarify deactivation process the catalysts was investigated upon catalytic test by UV-vis DRS. During the $\mathrm{CO}_{2}-\mathrm{PDH}$ process over $\mathrm{Cr}_{2.0} \mathrm{Si}$ Beta and $\mathrm{Cr}_{2.0} \mathrm{AlBeta}$ the spectra were collected in two time period. The first period between $0-1 \mathrm{~min}$ and second ones between $1-240 \mathrm{~min}$ on stream. The Fig. 9 summaries the spectra collected in these two periods.

In both cases, spectra of degassed in helium samples (fresh catalysts before $\mathrm{CO}_{2}-\mathrm{PDH}$ process) have two main maxima at $270 \mathrm{~nm}$ and $360 \mathrm{~nm}$ characteristic for CT transitions of $\mathrm{Cr}(\mathrm{VI})$ species. These maxima are reduced rapidly during first minute in contact with $\mathrm{CO}_{2}-\mathrm{C}_{3} \mathrm{H}_{8}$ mixture (Fig. 9A and C). Simultaneously, new broad bands between $650-700 \mathrm{~nm}$ appear indicating reduction of $\mathrm{Cr}(\mathrm{VI})$ to $\mathrm{Cr}(\mathrm{III}) / \mathrm{Cr}(\mathrm{II})$ species. The letter species were found to be catalytically active in non-oxidative dehydrogenation of hydrocarbons [56]. Their also involve in the dehydrogenation with $\mathrm{CO}_{2}[10,27,28]$. Ohisih et al. [59] have proposed redox cycle between $\mathrm{Cr}(\mathrm{II})$ and $\mathrm{Cr}(\mathrm{III})$ species in which $\mathrm{CO}_{2}$ acts as a mild oxidant. However, $\mathrm{CO}_{2}$ is very weak oxidant. As we found previously $\mathrm{Cr}(\mathrm{VI})$ species reduced with $\mathrm{CO}$ selectively to $\mathrm{Cr}$ (II) species are very slowly reoxidized by ultrapure $\mathrm{CO}_{2}$ (additionally deoxygenated and dry) [62] This may suggest that in the case of chromium-containing SiBeta catalyst an oxidation role of $\mathrm{CO}_{2}$ cannot be responsible alone for observed promoting effect.

In the second time period (between 1-240 min on stream) continuous rise of the intensity in whole range was observed that confirms a darkening of the sample due to coke formation. Tracking of the intensity variation at $1000 \mathrm{~nm}$ indicates that darkening of the catalysts is faster at the beginning of the process and slow down with TOS unlike to propylene yield (inset to Fig. 9B and D). This variation of coke formation rate with TOS can be explained based on higher reactivity of propylene than propane. Because coke is produced more easily from propene its high yield leads to faster deactivation. Similar effect was observed in propane dehydrogenation over $\mathrm{CrO}_{\mathrm{x}} / \mathrm{Al}_{2} \mathrm{O}_{3}[63,64]$.

Fig. 10 shows variation between initial propene yield (after $10 \mathrm{~min}$ on stream) and hydrogen consumption (from $\mathrm{H}_{2}$-TPR) that is proportional to number of redox $\mathrm{Cr}$ species for several various supported chromium oxide based catalysts including also $\mathrm{Cr}_{\mathrm{x}} \mathrm{SiBeta}$.

Over different $\mathrm{Cr}$-containing Beta materials the yield of propene rise with the number of redox $\mathrm{Cr}$ species which on various silicas depend on their pore structure and specific surface area of method of $\mathrm{Cr}$ incorporation/deposition as well as total $\mathrm{Cr}$ content. Typically, the yield rises with the increase of total $\mathrm{Cr}$ content up to the maximum value (monolayer coverage). After exceeding the monolayer coverage of support the redox $\mathrm{Cr}$ species are no longer stabilized (attached directly with support) and during the preparation there are decompose to less active and non-redox $\mathrm{Cr}_{2} \mathrm{O}_{3}$ particles. In $\mathrm{Cr}_{\mathrm{x}} \mathrm{SiBeta}$ series linear proportion between formation rate and number of redox species is observed up to $2 \mathrm{wt} \%$ of $\mathrm{Cr}$. After exceeding this content catalytic performance did not correlate further with number of redox sites. In this respect the $\mathrm{Cr}_{\mathrm{X}} \mathrm{SiBeta}$ catalysts exhibits quite different behavior than chromium ox- 
ide-based catalysts supported on ordered mesoporous silica (SBA-1 or SB-15). In the latter case propane rate was proportional to redox $\mathrm{Cr}$ species in wide range (between $07-13.6 \mathrm{wt} \%$ of $\mathrm{Cr}$ ) while in $\mathrm{Cr}_{\mathrm{x}} \mathrm{SiBeta}$ series the yield of propene reminds constant at and above $5 \mathrm{wt} \%$ of $\mathrm{Cr}$.

Finally, the effect of $\mathrm{CO}_{2}$ on catalytic performance was investigated. Fig. 11 shows the variation of formation rate of propene, carbon monoxide and hydrogen with TOS in the dehydrogenation of propane in the presence and absence of $\mathrm{CO}_{2}$, respectively. The switching process was carried out over $\mathrm{Cr}_{2.0} \mathrm{SiBeta}$ and $\mathrm{Cr}_{2.0}$ AlBeta catalysts.

Promoting effect of $\mathrm{CO}_{2}$ on formation rate of propene was observed over $\mathrm{Cr}_{2.0} \mathrm{SiBeta}$ catalyst. In each cycle with $\mathrm{CO}_{2}$ addition, the formation rate of propene was higher than in the cycles without it. Similar promoting effect was observed over chromium oxide-based catalysts supported on different pure siliceous supports, such as non-ordered $\mathrm{SiO}_{2}$ or ordered MCM-41, SBA-15, SBA-1, MSU-x [5,9-11,14,15,27,28]. Typically, $\mathrm{CO}_{2}$ addition enhances propene formation in comparison with $\mathrm{PDH}$ carried out using dilution with inert gas only $[5,27,28]$. Over $\mathrm{Cr}_{2.0}$ SiBeta, in $\mathrm{CO}_{2}$ presence, rises formation rate of propene and carbon monoxide while at the same time decreases formation rate of hydrogen. It should be pointed hear that addition $\mathrm{CO}_{2}$ never stops formation of hydrogen. Changes of formation rate of propene and hydrogen in cycles with and without $\mathrm{CO}_{2}$ are similar suggesting that positive effect of $\mathrm{CO}_{2}$ on propene production is due mainly due to shifting propane dehydrogenation equilibria via RWGS reaction. A good catalytic performance of Cr-containing catalysts in RWGS reaction was confirmed previously $[13,27]$. The equilibria calculations for two-step pathway of $\mathrm{CO}_{2}-\mathrm{PDH}$ process i.e. for $\mathrm{PDH}$ reaction coupling with RWGS reaction and for single $\mathrm{PDH}$ confirm that $\mathrm{CO}_{2}$ addition enhances significantly equilibrium conversion of propane [66]. Under reaction conditions applied in this work $\left(\mathrm{p}=1 \mathrm{~atm}, \mathrm{t}=550{ }^{\circ} \mathrm{C}\right.$ and feed with molar ratio $\mathrm{C}_{3} \mathrm{H}_{8}$ : $\mathrm{CO}_{2}$ :Inert $=1: 5: 9$ or $\mathrm{C}_{3} \mathrm{H}_{8}$ :Inert $=1: 14$ ) the equilibrium conversion of propane rise from $70 \%$ in $\mathrm{PDH}$ process to $89 \%$ in $\mathrm{CO}_{2}-\mathrm{PDH}$ process [2].

Taking in count above and considering very weak oxidative abilities of $\mathrm{CO}_{2}$ against reduced $\mathrm{Cr}$ species it can be conclude that over chromium-containing SiBeta catalysts propene is produced mainly by PDH pathways facilitated by hydrogen removing in RWGS. Propane oxidative dehydrogenation (PODH) pathway has small contribution because $\mathrm{CO}_{2}$ reoxidize very slowly reduced $\mathrm{Cr}$ species. Scheme 1 summarized both possible pathways responsible for $\mathrm{CO}_{2}$ promoting effect on formation rate of propene.

It should be pointed hear that the promoting effect observed in the case of $\mathrm{Cr}_{2.0} \mathrm{SiBeta}$ is similar to those observed on Cr-based catalysts supported on ordered or unordered mesoporous silicas. Over all these catalysts $\mathrm{CO}_{2}$ addition enhance only partially propene formation (10-25\%). Comparing to others catalytic systems, for instance palladium supported on Ce-based supports the promoting the effect of $\mathrm{CO}_{2}$ on Cr-based systems is moderate [3]. This variation of $\mathrm{CO}_{2}$ effect with catalyst can be explained by different contribution of PODH and PDH pathways. In the case of $\mathrm{Pd} / \mathrm{Ce}$-based catalysts a dissociation of $\mathrm{CO}_{2}$ to active $\mathrm{O}$ species and $\mathrm{CO}$ over ceria-based support facilitated both PODH and RWGS reactions, while over $\mathrm{Cr} /$ Silica based (or Si reach supports) catalysts such dissociation is not pronounced thus propene is produced mainly in PDH reaction.

In the contrast, over $\mathrm{Cr}_{2.0} \mathrm{AlBeta}$ reference catalyst $\mathrm{CO}_{2}$ exerts negative effect, e.g. the formation rate of propene drops in the process carried out with $\mathrm{CO}_{2}$. In this respect the $\mathrm{Cr}_{2.0} \mathrm{AlBeta}$ exhibits similar catalytic behavior to $\mathrm{CrO}_{\mathrm{x}} / \gamma-\mathrm{Al}_{2} \mathrm{O}_{3}$ catalyst $[2,5,11]$. In the latter case the poisoning effect of $\mathrm{CO}_{2}$ was assigned to strong $\mathrm{CO}_{2}$ adsorption on the surface of $\gamma-\mathrm{Al}_{2} \mathrm{O}_{3}$. FTIR investigation with $\mathrm{CO}_{2}$ as a probe molecule have revealed that on the surface of $\mathrm{CrO}_{\mathrm{x}} / \gamma-\mathrm{Al}_{2} \mathrm{O}_{3}$ carbon dioxide is strongly adsorbed in form of carbonates which may limit dehydrogenation of propane [2]. The quantitative $\mathrm{CO}_{2}$-TPD measurements show that amount $\mathrm{CO}_{2}$ adsorption on AlBeta is much higher than over dealu- minated form (SiBeta) (Table 1). This confirms stronger interaction of $\mathrm{CO}_{2}$ with AlBeta which may explain poisoning effect observed over the $\mathrm{Cr}_{2.0}$ AlBeta zeolite catalyst.

\section{Conclusions}

Catalytic performance of chromium-containing SiBeta catalysts was investigated in the dehydrogenation of propane to propene in $\mathrm{CO}_{2}$ assistance. Dealumination with acid nitrate leads to significantly reduction of $\mathrm{Si} / \mathrm{Al}$ module from 17 to 1000 . This has great impact on catalytic performance in $\mathrm{CO}_{2}$ - $\mathrm{PDH}$ process. A comparative catalytic results indicate that the promoting effect of $\mathrm{CO}_{2}$ propylene formation was observed on $\mathrm{Cr}_{2.0} \mathrm{SiBeta}$. On this dealuminated form of Beta zeolite both the yield and selectivity to propene rise in the presence of $\mathrm{CO}_{2}$. In contrasts, on $\mathrm{Cr}_{2.0}$ AlBeta zeolite catalyst $\mathrm{CO}_{2}$ exerts negative effect similar to poisoning effect observed over $\gamma-\mathrm{Al}_{2} \mathrm{O}_{3}$ based chromium oxide catalyst. Moreover, in series of $\mathrm{Cr}_{x}$ SiBeta catalysts a correlation between number of redox $\mathrm{Cr}$ species and catalytic performance was found.

\section{Declaration of Competing Interest}

None.

\section{References}

[1] https://www.economic-plant.com/component/tags/tag/polypropylene.html, (Accessed 14 June 2019).

[2] P. Michorczyk, K. Zeńczak, R. Niekurzak, J. Ogonowski, Pol. J. Chem. Technol. 14 (2012) 77-82.

[3] E. Nowicka, C. Reece, S.M. Althahban, K.M.H. Mohammed, S.A. Kondrat, D.J. Morgan, Q. He, D.J. Willock, S. Golunski, C.J. Kiely, G.J. Hutchings, ACS Catal. 8 (2018) 3454-3468.

[4] E. Gomez, S. Kattel, B. Yan, S. Yao, P. Liu, J.G. Chen, Nat. Commun. 9 (2018) 1398.

[5] I. Takahara, W. Chang, N. Mimura, M. Saito, Catal. Today 45 (1998) 55-59.

[6] X. Zhang, Y. Yue, Z. Gao, Catal. Lett. 83 (2002) 19-25.

[7] K. Nakagawa, C. Kajita, N. Ikenaga, M. Nishitani-Gamo, T. Ando, T. Suzuki, Catal. Today 84 (2003) 149-157.

[8] M. Botavina, G. Martra, Y. Agafonov, N. Gaidai, N. Nekrasov, D. Trushin, S. Coluccia, A. Lapidus, Appl. Catal. A: Gen. 347 (2008) 126-132.

[9] H. Li, Y. Yue, C. Miao, Z. Xie, W. Hua, Z. Gao, Catal. Commun. 8 (2007) 1317-1322.

[10] K. Takehira, Y. Ohishi, T. Shishido, T. Kawabata, K. Takaki, Q. Zhang, Y. Wang, J. Catal. 224 (2004) 404-416.

[11] M. Kocoń, P. Michorczyk, J. Ogonowski, Catal. Lett. 101 (2005) 53-57.

[12] Y. Wang, Y. Ohishi, T. Shishido, Q. Hang, K. Takehira, Stud. Surf. Sci. Catal. 146 (2003) 725-728.

[13] P. Michorczyk, J. Ogonowski, React. Kinet. Catal. Lett. 87 (2005) 177-183.

[14] P. Michorczyk, J. Ogonowski, P. Kuśtrowski, L. Chmielarz, Appl. Catal. A: Gen. 349 (2008) 62-69.

[15] L. Liu, H. Li, Y. Zhang, Catal. Commun. 8 (2007) 565-570.

[16] Y. Wang, Y. Ohishi, T. Shishido, Q. Zhang, W. Yang, Q. Guo, H. Wan, K. Tkehira, J. Catal. 220 (2003) 347-357.

[17] H. Xiao, J. Zhang, P. Wang, X. Wang, F. Pang, Z. Zhang, Y. Tan, Catal. Sci. Technol. 6 (2016) 5183-5195.

[18] P. Michorczyk, J. Ogonowski, Appl. Catal. A: Gen. 251 (2003) 425-433.

[19] B. Xu, B. Zheng, W. Hua, Y. Yue, Z. Gao, J. Catal. 239 (2006) 470-477.

[20] B. Zheng, W. Hua, Y. Yue, Z. Gao, J. Catal. 232 (2005) 143-151.

[21] F. Zhang, C. Miao, Y. Yue, W. Hua, Z. Gao, Chin. J. Chem. 30 (2012) 929-934.

[22] M. Chen, J. Xu, Y.M. Liu, Y. Cao, H.Y. He, J.H. Zhuang, K.N. Fan, Catal. Lett. 124 (2008) 369-375.

[23] M. Chen, J. Xu, F.Z. Su, Y.M. Liu, Y. Cao, H.Y. He, K.N. Fan, J. Catal. 256 (2008) 293-300.

[24] P. Michorczyk, P. Kuśtrowski, L. Chmielarz, J. Ogonowski, React. Kinet. Catal. Lett. 82 (2004) 121-130.

[25] X.-L. Xue, W.-Z. Lang, X. Yan, Y.-J. Guo, ACS Appl. Mater. Interfaces 9 (2017) 15408-15423.

[26] I. Takahara, M. Saito, M. Inaba, K. Murata, Catal. Lett. 102 (2005) 201-205.

[27] P. Michorczyk, P. Pietrzyk, J. Ogonowski, Microporous Mesoporous Mater. 161 (2012) 56-66.

[28] P. Michorczyk, J. Ogonowski, K. Zenczak, J. Mol. Catal. A: Chem. 349 (2011) $1-12$.

[29] S. Wang, K. Murata, T. Hayakawa, S. Hamakawa, K. Suzuki, Appl. Catal. A: Gen. 196 (2000) 1-8.

[30] X. Ge, M. Zhu, J. Shen, React. Kinet. Catal. Lett. 77 (2002) 103-108.

[31] N. Mimura, I. Takahara, M. Inaba, M. Okamoto, K. Murata, Catal. Commun. 3 (2002) 257-262. 
[32] P. Kuśtrowski, P. Michorczyk, L. Chmielarz, Z. Piwowarska, B. Dudek, J. Ogonowski, R. Dziembaj, Termochim. Acta 471 (2008) 26-32.

[33] J.B. Higgins, R.B. LaPierre, J.L. Schlenker, A.C. Rohrman, J.D. Wood, G.T. Kerr, W.J. Rohrbaugh, Zeolites 8 (1988) 446-452.

[34] S.-B. Liu, J.-F. Wu, L.-J. Ma, T.-C. Tsai, I. Wang, J. Catal. 132 (1991) 432-439.

[35] Y. Zhang, Y. Li, J. Gu, S. Tian, P. Ning, Korean J. Chem. Eng. 35 (2018) 1932-1940.

[36] M.A. Camblor, A. Corma, J. Perez-Pariente, Zeolites 13 (1993) 82-87.

[37] E.P. Reddy, L. Davydov, G. Smirniotis, Panagiotis, J. Phys. Chem. B 106 (2002) 3394-3401.

[38] A. Rokicińska, M. Drozdek, B. Dudek, B. Gil, P. Michorczyk, D. Brouri, S. Dzwigaj, P. Kuśtrowski, Appl. Catal. B: Environ. 212 (2017) 59-67.

[39] K.A. Chalupka, W.K. Jozwiak, J. Rynkowski, W. Maniukiewicz, S. Casale, S. Dzwigaj, Appl. Catal. B 146 (2014) 227-236.

[40] S. Dzwigaj, P. Massiani, A. Davidson, M. Che, J. Mol. Catal. A 155 (2000) 169.

[41] S. Dzwigaj, M.J. Peltre, P. Massiani, A. Davidson, M. Che, J. Chem. Soc. Chem. Commun. 87 (1998)

[42] S. Dzwigaj, M. Matsuoka, R. Franck, M. Anpo, M. Che, J. Phys. Chem. B 102 (1998) 6309.

[43] S. Dzwigaj, M. Che, J. Phys. Chem. B 110 (2006) 12490.

[44] S. Dzwigaj, M. Matsuoka, R. Franck, M. Anpo, M. Che, J. Phys. Chem. B 110 (2006) 12490.

[45] S. Dzwigaj, P. Massiani, A. Davidson, M. Che, J. Mol. Catal. A: Chem. 155 (2000) 169-182.

[46] R. Baran, Y. Millot, T. Onfroy, J.-M. Krafft, S. Dzwigaj, Microporous Mesoporous Mater. 163 (2012) 122-130.

[47] R. Hajjar, Y. Millot, P.P. Man, M. Che, S. Dzwigaj, J. Phys. Chem. C 112 (2008) 20167-20175.

[48] S. Dzwigaj, Y. Millot, C. Méthivier, Michel Che, Microporous Mesoporous Mater. 130 (2010) 162-166.
[49] G.L. Woolery, L.B. Alemany, R.M. Dessau, A.W. Chester, Zeolites 6 (1986) 14-16.

[50] L.W. Beck, J.F. Haw, J.L. White, J. Am. Chem. Soc. 116 (1994) 9657-9661.

[51] P.I. Kyriienko, O.V. Larina, N.O. Popovych, S.O. Soloviev, Y. Millot, S. Dzwigaj, J. Mol. Catal. A: Chem. 424 (2016) 27-36.

[52] B.M. Weckhuysen, I.E. Wachs, R.A. Schoonheydt, Chem. Rev. 96 (1996) 3327-3350.

[53] M. Lezanska, G.S. Szymanski, P. Pietrzyk, Z. Sojka, J.A. Lercher, J. Phys. Chem. C 111 (2007) 1830-1839.

[54] A.G. Gaspar, L.C. Dieguez, J. Catal. 220 (2003) 309-316.

[55] A.G. Gaspar, J.L.F. Brito, L.C. Dieguez, J. Mol. Catal. A: Chem. 203 (2003) 251-266.

[56] A. Hakuli, M. Harlin, L. Backman, O. Krause, J. Catal. 184 (1999) 349-356.

[57] M. Gierada, P. Michorczyk, F. Tielens, J. Handzlik, J. Catal. 340 (2016) 122-135.

[58] C.S. Kim, S.I. Woo, J. Mol. Catal. 73 (1992) 249-263.

[59] Y. Ohishi, T. Kawabata, T. Shishido, K. Takaki, Q. Zhang, Y. Wang, K. Takehira, J. Mol. Catal. A: Chem. 230 (2005) 49-58.

[60] J.F.S. de Oliveira, D.P. Volanti, J.M.C. Bueno, A.P. Ferreira, Appl. Catal. A: Gen. 558 (2018) 55-66.

[61] F. Zhang, R. Wu, Y. Yue, W. Yang, S. Gu, C. Miao, W. Hua, Z. Gao, Microporous Mesoporous Mater. 145 (2011) 194-199.

[62] P. Michorczyk, J. Ogonowski, Chem. Commun. 48 (2012) 7283-7285.

[63] R.L. Puurunen, B.G. Beheydt, B.M. Weckhuysen, J. Catal. 204 (2001) 253-257.

[64] R.L. Puurunen, B.M. Weckhuysen, J. Catal. 210 (2002) 418-430.

[65] P. Michorczyk, J. Ogonowski, M. Niemczyk, Appl. Catal. A: Gen. 374 (2010) $142-149$.

[66] M.A. Atanga, F. Rezaei, A. Jawad, M. Fitch, A.A. Rownaghi, Appl. Catal. B: Environ. 220 (2018) 429-445. 